Portland State University

PDXScholar

2014

\title{
Music and Acculturation: Using Culture-focused Music Therapy to Address the Adverse Effects of Acculturative Stress
}

Christopher A. Arnold

Portland State University

Follow this and additional works at: https://pdxscholar.library.pdx.edu/honorstheses

Let us know how access to this document benefits you.

\section{Recommended Citation}

Arnold, Christopher A., "Music and Acculturation: Using Culture-focused Music Therapy to Address the Adverse Effects of Acculturative Stress" (2014). University Honors Theses. Paper 82.

https://doi.org/10.15760/honors.83

This Thesis is brought to you for free and open access. It has been accepted for inclusion in University Honors Theses by an authorized administrator of PDXScholar. Please contact us if we can make this document more accessible: pdxscholar@pdx.edu. 
Running head: MUSIC AND ACCULTURATION

\author{
Music and Acculturation: \\ Using Culture-focused Music Therapy to \\ Address the Adverse Effects of Acculturative Stress
}

by

Christopher A. Arnold

An undergraduate honors thesis submitted in partial fulfillment of the requirements for the degree of

Bachelors of Arts

in

University Honors

and

Psychology

Thesis Adviser

Ann Marie Fallon

Portland State University

2014 


\section{Acknowledgments}

I wish to express my deepest respect and gratitude to Dr. Ann Marie Fallon, for her wisdom, guidance, and ceaseless support over the entire span of my collegiate experience; to Dr. Robert Ryan, for sharing his rich and invaluable knowledge of Native American culture, and for providing the initial inspiration for this project; and to Niso Caywood, for sharing his meaningful insight and knowledge of Native American culture, for his story, his support, and of course the music and the friendship. Devoid of the assistance of these individuals, this project would have surely been insurmountable. 


\section{Table of Contents}

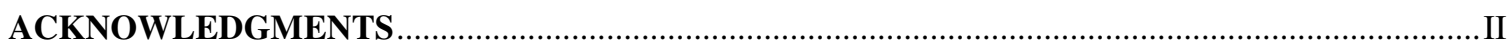

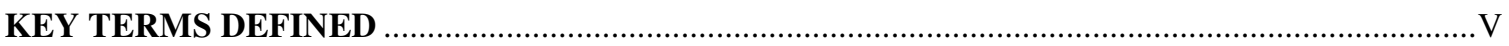

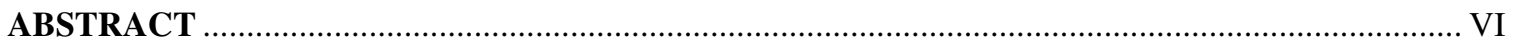

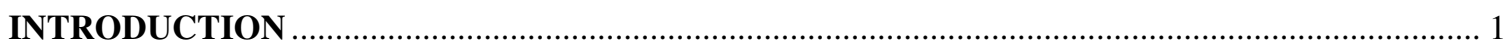

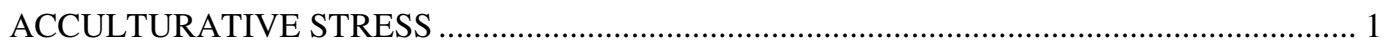

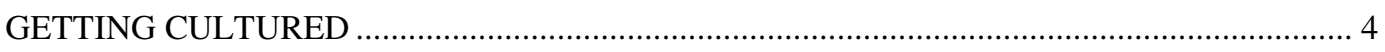

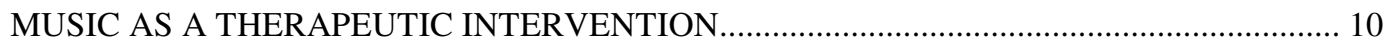

A CULTURE-FOCUSED MUSIC THERAPY PROGRAM ………….................................... 11

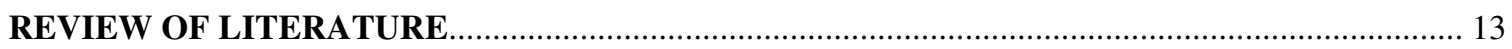

ACCULTURATIVE STRESS AND PSYCHOLOGICAL FUNCTIONING ……....................... 15

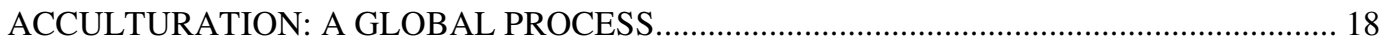

ACCULTURATION AND NATIVE AMERICAN POPULATIONS ……...................................... 24

THE RESILIENCY OF THE NATIVE AMERICAN PEOPLE ................................................. 31

EN ROUTE TO A CULTURE-FOCUSED MUSIC THERAPY PROGRAM................................ 34

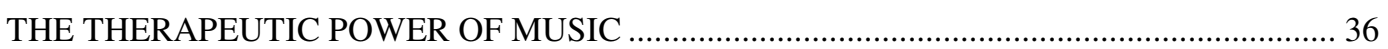

MUSIC AND NATIVE AMERICAN CULTURE ………......................................................... 42

HYPOTHETICAL PROGRAM DESIGN AND IMPLEMENTATION ........................................ 48

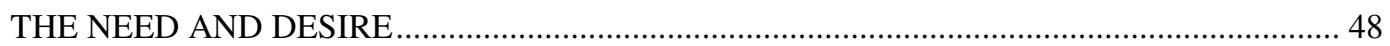

SCHEMATICS OF A CULTURE-FOCUSED MUSIC THERAPY PROGRAM ........................ 50

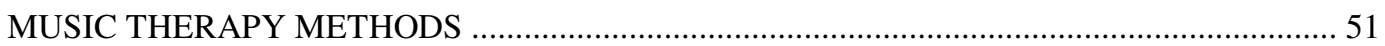


METHODS OF CULTURAL EDUCATION AND EMPOWERMENT ……………………...... 56

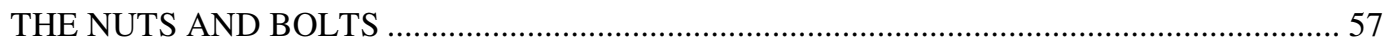

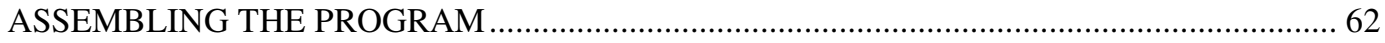

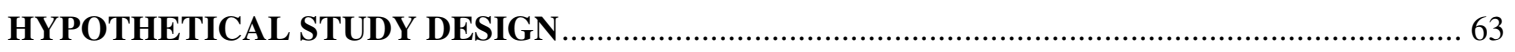

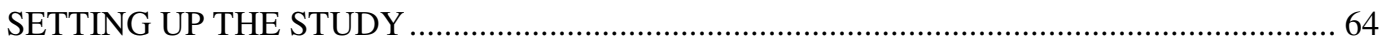

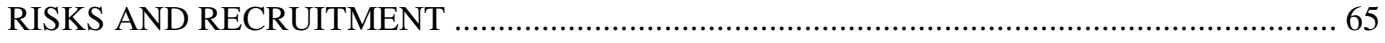

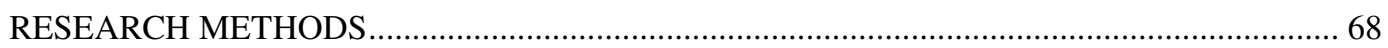

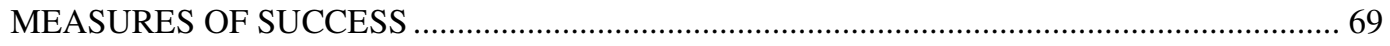

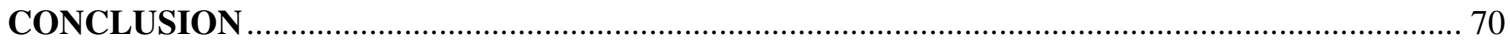

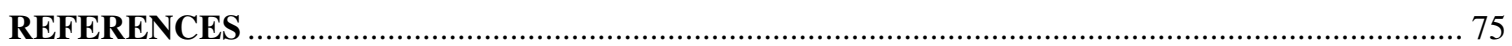




\section{Key Terms Defined}

Acculturative stress- Psychological stress induced by acculturation, or the process of assimilating from a minority group culture to a dominant majority group culture. Acculturative stress can manifest from many difficulties of acculturation including incompatible cultural values, language difficulties, familial strain, loss of identity, and discrimination.

Music therapy- A clinical and evidence-based therapeutic intervention program utilized for a variety of mental and physical health issues (AMTA, 2013). One partaking in music therapy may listen to, dance to and/or analyze music; one might learn about various kinds of music; one might learn how to play and perform various kinds of music; and one may even learn to write music within various genres.

Culture-focused music therapy- I have defined this term as a therapeutic intervention program wherein individuals interact with the music associated with their heritage ethnic identity. The music interaction would be similar to that which exists in standard music therapy programs (see above) however there would be a greater emphasis on cultural education and empowerment through learning about and partaking in music from one's own historical ethnic background. In this construct, the intervention affects healing on multiple levels: through the use of music engagement, as well as heritage ethnic cultural education and empowerment. 


\begin{abstract}
More than any other demographic in the United States, Native American populations experience the highest rate of suicide proportional to population size. This is just one of numerous statistics indicative of the overall status of Native American psychological health. There has been increasing research demonstrating that Native American suicide rate and depression is positively associated with acculturative stress, and negatively associated with traditional heritage cultural integration. Because an increased amount of acculturative stress for Native Americans is correlated with high suicide rate and occurrence of depression, while increased traditional culture integration may be linked to lower suicide rate and occurrence of depression, psychological intervention programs designed for Native Americans could benefit from exploring methods of decreasing acculturative stress while increasing heritage culture retention and exposure. Among the most central aspects of traditional Native American culture (and most cultures throughout human history) is the meaningful inclusion of music. Because music is a construct so intrinsic to the historical human experience, research has shown music as a form of therapy to be a vastly effective means of intervention for a wide variety of psychological issues. Combining the concept of traditional culture retention and exposure together with the construct of music therapy is an effective means of combating acculturative stress for Native American populations. The implementation of this "culture-focused music therapy program" would reduce acculturative stress by increasing and enriching traditional heritage culture identity for Native American individuals under psychological distress, thereby leading to an increase in overall psychological welfare.
\end{abstract}




\section{Introduction}

Acculturative Stress

Native American populations arguably experience among the poorest standard of living among any population group in the United States. Today, Native American populations experience the highest rate of suicide across all age groups, the most cases of PTSD, the most cases of serious psychological distress, and the highest rate of drug and alcohol abuse compared to any other population group in the country. Among these dismal statistics are the added concerns of exceptionally high rates of anxiety and depression. Research also demonstrates that Native American populations experience significant levels of continuous historical trauma, they experience severe psychological distress 1.5 times more frequently than the general population, they experience PTSD more than twice as often as the general population, and they use and abuse drugs and alcohol at younger ages and higher rates than any other ethnic demographic in the United States (APA, 2010; Suicide Prevention Resource Center, 2013).

Though these statistics represent a grim reality for many Native American individuals, other minority groups in the United States see aggravated levels of many of these same mental health issues as well. In fact, many of these mental health issues facing Native Americans and numerous other ethnic minority groups have been associated with the same sociocultural process, namely the process of acculturation.

Research has demonstrated that the process of transitioning from an ethnic minority culture group and assimilating into a majority culture group is associated with various negative psychological and behavioral outcomes (Berry, 1997; Berry, 2006; Buriel et al., 1982; Marielena et al., 2005; Lester, 1999). Higher acculturation integration 
has been positively associated with increased levels of delinquency, drug abuse, alcohol abuse, poor dietary and nutrition patterns, teen pregnancy, poor perinatal outcomes (prematurity, low birth weight, neonatal mortality, etc.), feelings of rejection and discrimination, and increased levels of overall stress, depression, anxiety, and rates of suicide (Berry, 1997; Buriel et al., 1982; Lester, 1999; Marielena et al., 2005; Szapocznik, 1980).

Acculturative stress could be consequent on a multiplicity of varied factors, such as incompatible cultural values and practices between one's heritage culture and the target dominant culture of assimilation, language difficulties, discrimination, familial tension (resulting of discrepancies between second-generation more acculturated youth and their less acculturated elders and family members), and feeling a sense of rejection or alienation from peer groups and/or family members (Gil, 1994; Miranda, 2006). All of these indications of increased acculturative stress can lead to a reduced state of overall psychological well-being.

To add to this trend, research has also demonstrated that a higher level of heritage cultural retention is negatively associated with acculturative stress factors (Bradway, 2011; Lester, 1999). This means that as ethnic minority group individuals further acculturate into the dominant culture group, acculturative stress factors increase in occurrence. However, when an individual is less acculturated within the dominant culture group, and more acculturated within their own heritage ethnic minority culture group, these acculturative stress factors seem to diminish. This paints a striking picture of the relationship between acculturative stress and the degree of acculturation with one's 
heritage ethnic culture group. This relationship suggests that stronger heritage culture identification can assist in reducing the effects of acculturative stress.

Besides heritage culture identification, an important factor in mitigating the effects of acculturative stress is the level of one's resiliency. Occasional overwhelming hardships in life are a central aspect of living. However the ability to withstand and recoil from life's hardships, and to thrive in the aftermath is a key feature of resiliency. Interestingly, for Native American populations, resiliency appears to be a cultural phenomenon.

Research has demonstrated that the single strongest predictor of resiliency for Native American groups is the strength of the culture, and that resiliency in itself is a byproduct of Native American culture. Further, this same research has demonstrated that the resiliency found as a byproduct of Native American culture is a form of uniquely robust resilience, further indicating that traditional ethnic culture retention is a protective factor in combating acculturative stress (Bradway, 2011).

Because Native American individuals suffer a "disproportionate burden of mental health problems and disorders" (APA, 2010), and because most of those mental health issues have been associated with acculturative stress, Native American individuals could address these mental health problems and disorders by examining their exposure to acculturative stress. Further, because traditional culture retention is associated with reduced levels of acculturative stress, and, for Native American individuals, increased robust resiliency, it follows that Native American individuals could greatly benefit from increasing their exposure with their own heritage traditional culture in attending to acculturative stress. 
Getting Cultured

The solution to combating acculturative stress for Native American individuals seems entirely straightforward: Increase heritage culture retention and exposure to decrease acculturative stress. However, the current cultural situation surrounding Native American populations is a vastly complex and sensitive one. It is not always a simple undertaking for Native American individuals to get in touch with their traditional heritage culture (American Indian Policy Center, 2005). The present day sociocultural landscape for many Native American individuals is the result of years of persecution with the goal of entirely obliterating Native American culture. This has resulted in a significant and nearly irreversible loss of traditional culture knowledge, lasting feelings of shame in regards to ethnic identity, and a history of necessity to acculturate to mainstream Western culture society in order to survive (American Indian Policy Center, 2005). It is perhaps astounding that some traditional aspects of Native American culture, such as language, music and sacred ceremonies, have survived at all given that they were faced with constant and deliberate attempts of annihilation.

The historical colonization process by White European Americans initiated a fullscale genocide, followed by attempts to assimilate, destroy or "civilize" Native American culture. Garret and Pichette (2000) defined the process starkly as a campaign to "kill the Indian, save the man" (p. 4). This truly deplorable historical fate carried over across multiple generations, and when paired with the present day landscape of acculturative stress factors, prejudice and discrimination, the Native American sense of identification and well-being is profoundly affected (Schiefer \& Krahé, 2014). 
Another aspect challenging traditional culture integration is the difficulty for younger generations to become engaged within their heritage traditional culture under the constant influence of mainstream Western culture. Young Native American individuals' lives are permeated by mainstream society on all fronts through media use, social pressures, the ease of technology, and modern educational system influences. Though it is especially noticeable in the lives of younger generations, mainstream Western society is a force repelling Native American individuals across all age groups away from their traditional heritage culture (American Indian Policy Center, 2005).

An additional feature contributing to the difficulty of traditional culture retention for Native American individuals is that after hundreds of years of cultural persecution, many Native Americans today find themselves not only psychologically, emotionally or spiritually separated, but also physically separated from their traditional culture. In the $21^{\text {st }}$ century, nearly two-thirds of Native Americans live in urban, Western culturedominated areas ("Revitalizing Native Cultures", 2006). This culminates in many modern day Native Americans losing contact with reservations and other members of their heritage culture, making reinforcement and expression of their traditional culture very difficult. Currently, it is a challenge for many Native American individuals who wish to engage with their own heritage traditional culture; often the closest they can come to their heritage culture is the "big city" pow wows, where important cultural aspects such as costumes and dances are simply "reduced to pan-Indian stereotypes" (“Revitalizing Native Cultures", 2006, p. 1).

Traditional culture survives best in reservation sites or Native American communities wherein Native American individuals are still living and working together 
and trying to retain aspects of their culture. However, even in reservation or Native American communities, the influence of dominant Western culture can still pervade. This is yet another aspect making traditional culture retention difficult for Native American individuals in the modern era. The infusion of the dominant Western culture has proved hard to resist even in reservation sites wherein traditional culture retention is a priority.

An example of this persistent pervasion of Western culture in the face of attempted traditional culture retention is evidenced in the Eastern Band of the Cherokee Nation and their traditional "stick ball game". The game is a pastime that goes far back into the culture's history. Today, though the Eastern Band of the Cherokee Nation tries to keep the tradition alive, the game cannot compete with other Western culture sporting events. The traditional stick ball game is now only played once a year at the Eastern Band of the Cherokee Nation's annual Indian Fair, while the local high school football team draws a significant amount of attention year-round. Coach Scooter McCoy, who is an Eastern Band of the Cherokee Nation member, put it simply when he stated, “American football is our modern stickball” ("Revitalizing Native Cultures", 2006, p. 1). This demonstrates the slow extinction and/or conversion of traditional cultural aspects in favor of modern Western culture aspects. This is a potentially harmful development; recall that decreased heritage culture identification is associated with higher levels of acculturative stress.

Because these impediments of traditional Native American culture retention appear so grim, it is made all the more glaring that traditional Native American culture retention deserves a call for action, especially given that traditional culture retention 
could help combat the many negative effects of acculturative stress. Though it is a difficult endeavor, there have been movements that seek to revitalize traditional Native American culture.

One such method of traditional Native American culture regeneration has been the process of language revitalization. Language, much like music, is an integral aspect of the human experience, and is close to the very core of culture and identity. Pechanga tribal chief Mark Macarro speaks of language in Native American culture, stating that it is "a key to the soul of the culture" ("Revitalizing Native Culture", 2006, p. 2). The disappearance of Native American language is a detrimental blow to traditional culture, because language is part of the deeply rooted identity of the culture. As such, the loss of language is both a symbolic and literal loss of a culture ("Revitalizing Native Culture", 2006). The number of Native languages spoken in the United States was once in the thousands, while today the number sits somewhere between 150 and 175 (Downs, Nguyen, \& Johnson, 2013). Copious amounts of languages have been lost over time, and many of these languages have become permanently lost, as some have disappeared without a trace before they could be documented in any form ("Revitalizing Native Culture", 2006).

The loss of traditional culture aspects has begun to take a more prominent role in contemporary literature. Today there are many programs, both tribal and governmental, which seek to revitalize Native American language with the goal of traditional culture revival. Such programs utilize linguistic materials in the form of writings, early recordings, and what little elder knowledge of language remains. The efforts of these programs include compiling dictionaries and other linguistic resources, practical 
immersion language courses (some tribes offer classes to youth wherein they only speak the traditional language with elders for extended periods of time), the creation of informative videos in collaboration with tribal historians, and even recreating languages from scratch based on wax recordings (Downs et al., 2013; "Revitalizing Native Culture", 2006). The National Endowment for the Humanities (NEH) has partnered with tribes all over the United States in a mission to support "strategic collaborations in Native American history, languages, and cultural revitalization" (Downs et al., 2013).

Language is a central aspect of culture, and it would appear that Native American tribes and government institutions are recognizing and actively pursuing language rejuvenation as a means of traditional Native American culture retention. This is a crucial step in impacting acculturative stress, as revitalization of traditional heritage culture integration and identity is vital to mitigate acculturative stress. Though this is undoubtedly important work, there is another core aspect of culture that could positively influence traditional heritage culture integration.

Much like language, music is one of the most primordial activities in the human experience. In fact, every known human culture on Earth within at least the last 50,000 years has evolved around some design of musical framework (Wallin, 2001). Given this inextricable link between music and culture, it is not difficult to conceptualize that creating cultural change, such as increasing traditional heritage culture exposure, might greatly benefit from the use of a construct as deeply ingrained in and important to culture as is music.

Native American culture specifically has a rich, deep, and meaningful history of music. Music was traditionally created for specific ceremonial and religious purposes to 
accompany dances, ritual and prayer. This suggests that music held a high position of significance, as religious aspects of culture are historically deeply important to the construct of culture (Prinzing, 2009). In fact, music lies at the very heart of Native American culture. In many traditional Native American cultures, the entire life span is framed by music. All occasions, whether sacred or secular, personal or tribal, are thoroughly inextricable with the music of traditional Native American culture. In addition to meaningful religious and ceremonial purposes, music was also an integral feature of healing, work, play, hunting, courtship, storytelling, war, and social interactions and dances (Wishart, 2011).

Music truly pervaded into the core of Native American traditional culture, and as such, music is a vastly important cultural aspect in traditional Native American culture. Just as programs today offer considerable attention to language revitalization as a vessel of traditional culture retention and exposure, music should exist as a prominent utilization of traditional culture retention. This may be especially true for a culture as historically inextricable with musical constructs as traditional Native American cultures. Recall that traditional culture integration is associated with reduced acculturative stress, and therefore better psychological functioning. Given that music historically holds such weight in Native American culture, it is conceivable that traditional culture integration, reduced acculturative stress and better psychological functioning are achievable by employing music as the therapeutic device for traditional culture exposure. 


\section{Music as a Therapeutic Device}

In recent decades, researchers have begun to explore the association between music, the mind, the body and overall health. A considerable amount of contemporary research has demonstrated the incredible and diverse effects music can have on psychological and physical health, indicating an innate connection between mental health, overall well-being, the human mind and music. As a result of the continuously positive experimentation of music and music-associated health benefits, research has analyzed an immense variety of mental health issues over many diverse populations to better understand the potential of music as a means of therapeutic intervention (De Backer, 2005; Grocke et al., 2009; Hamill, 2009; Hinton, 2008; Sacks, 2008).

There has been a long history of utilizing music as a healing force outside of the research field. In fact, music used as a healing mechanism has been documented since the beginning of recorded history (Wiand, 2004). Shamanism, widely regarded as one of the oldest forms of healing, frequently used sound and music to access and communicate with the spiritual world. Shamans, philosophers and mystics throughout recorded history have utilized music as a balancing and unifying source; a source that was viewed to heal and bring wholeness to the body, the mind, the psyche, nature, and the universe. This type of shamanistic use of music as a form of healing still exists and thrives today in many indigenous and tribal communities throughout the entire world (Wiand, 2004).

Still, though experimentation with music has yielded positive results in healing potential, and though there has been a global history of music as a form of healing, research had historically seldom considered music as an agent of psychological healing (Koen, 2013). However in more recent years, music as a therapeutic intervention and as 
a healing process has seen an increase in public attention and within the research field. Today, evidence-based clinical research demonstrates the efficacy of music as a form of therapy in helping combat intense mental and physical health issues (Young-Mason, 2002). Controlled treatment outcome studies have shown that listening to and playing music is a potent treatment for multitudinous mental health issues. Additionally, adding music therapy to mental health treatment greatly improves social functioning and reduces symptoms amongst schizophrenic individuals. Further, music therapy has displayed efficacy as an independent treatment for reducing anxiety, depression, and chronic pain (Friedman, 2014).

Research continues to demonstrate that, as both a stand-alone treatment and a supplemental treatment, music can help improve psychological functioning and wellbeing. However, in the current research landscape, the process of combating acculturative stress does not appear to have been linked with the healing potential of music.

\section{A Culture-focused Music Therapy Program}

Because acculturative stress has been associated with so many adverse mental health outcomes, it might be surprising that there is little mention of specific therapeutic intervention processes in combating acculturative stress in the extant literature field. As evidenced by the grim statistics regarding Native American populations, the mental health effects associated with acculturative stress is a dire issue that requires immediate attention and effective intervention. It is at this issue where several aspects discussed thus far come to a position of collaboration. 
In review, acculturative stress is a process that can result in many exceedingly grave psychological and behavioral outcomes and reduced overall well-being. Acculturative stress has been associated with a loss of traditional heritage culture identity, and increased heritage culture identity has been associated with better psychological well-being. It follows then that increasing traditional heritage culture exposure and retention could mitigate the associated mental health effects of acculturative stress.

Music is an aspect that is at the very core of most cultures; therefore music is an important and integral cultural construct. As such, music itself could be a productive means of traditional heritage culture exposure. Further, music has been shown to be a vastly effective therapeutic device in myriad mental health situations.

The concepts of traditional heritage culture reinvigoration and music as a culture and psychological healing force logically fit together and compliment each other. At this point the theory forms that perhaps music can be utilized as a therapeutic device to combat acculturative stress by empowering and reinvigorating traditional heritage identity while simultaneously providing all the benefits of music as an independent force of healing. It is here that the proposed "culture-focused music therapy" program emerges to mitigate the harmful effects of acculturative stress.

Electing to work with Native American populations as the ideal population of focus for this proposed culture-focused music therapy program is consequent on many cogent reasons that have been outlined up to this point. First, Native American populations experience a preponderance of mental health and behavioral problems attributed to acculturative stress compared to any other ethnic demographic. 
Additionally, research with Native American populations and the process of acculturation has been tragically underrepresented. Further, because research suggests that reintegration into traditional Native American culture will not only combat acculturative stress, but could also result in the acquisition of a specialized cultural resiliency. Lastly, because Native American culture is one that has historically been exceptionally closely involved with a meaningful inclusion of music. All of these reasons create a convincing case that Native American populations are the ideal candidates for analyzing the efficacy of a culture-focused music therapy program to mitigate acculturative stress, and, more importantly, that Native American individuals may experience profound healing in the participation of such a program.

In furthering this concept, a review of the literature follows to outline specific extant research in the fields of acculturation and acculturative stress, Native American culture, and music as a therapeutic measure.

\section{Review of Literature}

The topic of acculturation has been an area of research interest for many years, and as a result, the data and research around the subject is fairly abundant. However historically, the topic of acculturation effects has been one of some controversy in the research field. One such issue of potential controversy as outlined by Ngo (2008) is the notion that "the processes of acculturation are complex and have often been dealt with in the literature in confusing and inconsistent ways" (Introduction section, para. 1). The literature calls for a system of generalized definitions and structural components to help clarify the research and bring consistency to the field. Researchers now attempt to code 
conditions of acculturative stress, and to establish a more structured language around acculturation by providing definitions to new terms and concepts (Berry, 1997). Further, current research contributes more to the discourse of meta-analysis of existing data to analyze the significance of acculturation data (Marielena, 2005).

Also of potential concern is the population focus of the literature dealing with acculturation. Acculturation research has largely focused on a few specific population groups of immigrants (Schiefer \& Krahé, 2014). Though this research is vastly important, it is also important to understand how acculturation affects a diversity of people. Additionally, if acculturation effects are found to be largely universal across many different social, cultural and ethnic conditions, then the associated psychological outcomes can be more closely related to the actual process of acculturation rather than confounds related to differences in social, cultural and ethnic conditions.

Studies have analyzed many cultures from around the world in an effort to code global acculturative factors. Yet it remains true that there has been very little identifiable literature in regards to Native American populations and acculturative stress in the existing research field. Most of these studies deal with immigrant groups, however an interesting aspect of Native American acculturation in the United States is that Native American populations by definition are not immigrants to this country; they in fact come from a lineage of native inhabitants. (Schiefer \& Krahé, 2014). Research on mental health in Native American populations is extremely limited due to the small population size (about $1.5 \%$ of the entire United States population) and the heterogeneity of the overall population (APA, 2010). Given this apparent gap in the literature, it is only made more apparent that inadequate attention in the research field has been granted to the 
process of acculturation within Native American populations. Because Native American populations experience some of the highest rates of mental health issues associated with acculturative stress, it is clear that the need exists for further research of acculturation effects within this population.

Though lacking in Native American population research, the literature dealing with the process of acculturation does yield some very important and useful studies for understanding the complex interplay between the process of acculturation, acculturative stress and psychological functioning.

\section{Acculturative Stress and Psychological Functioning}

The process of acculturation itself is an incredibly elaborate system. To analyze acculturation and its exchange with something as complex as psychological functioning further augments the intricacy of study. Crockett et al. (2007) studied this complicated relation between acculturative stress and psychological functioning while also paying close attention to the gaps in the acculturation literature around social support systems and coping strategies.

In their study, Crockett et al. (2007) worked with a small sample $(N=148)$ of Mexican American college students in California and Texas. Through bivariate analyses, the study found that acculturative stress is associated with higher levels of anxiety and depressive symptoms. In addressing the relationship of social support systems and coping strategies within acculturative stress effects, the study found that active coping predicted better adjustment (lower levels of depression) while avoidant coping predicted poor adjustment (higher levels of depression and anxiety). Additionally, tests of 
interaction effects demonstrated that active coping, and parental/peer support assuage the effects of high acculturative stress on anxiety and depressive symptoms.

This study is useful in that it clearly and plainly illustrates the strong positive relationship between acculturative stress and mental health issues (in this case represented by levels of depressive symptoms and anxiety). Also, the study identifies two independent factors that work to reduce acculturative stress effects, namely social support and coping strategy.

Social support can arguably be regarded as a factor of heritage ethnic identity retention, as much of social support comes in the form of familial and parental guidance. In a typical scenario, it is likely that family and parental support would align more with traditional ethnic identity retention for ethnic minority individuals, as the system would be influenced by multiple generations of traditional culture exposure. Peer group social support could be a vessel of heritage ethnic identity exposure, but it could also be a product of national identity exposure for ethnic minority individuals. Especially for younger ethnic minority individuals, the process of acculturation often involves expanding one's peer group to include members of various cultures, including those individuals belonging to the target culture of assimilation. In this case, national identity exposure could be alleviating some acculturative effects. However, the study found that parental support was especially effective in moderating acculturative effects, and parental support was much more consistent in moderating acculturative effects. Additionally, parental support moderated both measures of acculturative stress, combating depressive symptoms as well as anxiety. Peer support only helped in the reduction of anxiety, and it 
did so with less consistency than what parental support did for both anxiety and depressive symptoms.

So although peer support (which could easily be a construct of national identity exposure or ethnic identity exposure) does do something to alleviate acculturative effects, parental support (which would more than likely be a result of ethnic identity exposure in most ethnic minority group experiences) is a far more consistent and effective means of social support in thwarting the effects of acculturative stress. This suggests that heritage ethnic identity retention is an effective means of moderating the adverse effects of acculturative stress. Additionally, this falls in line with the previously mentioned factor of familial strain as a byproduct of acculturative stress. If familial tension can help to cause acculturative stress then it follows that familial support could help mitigate the effects of acculturative stress.

Also of importance in alleviating acculturative stress, as demonstrated in the Crockett et al. (2007) study, is the system of coping strategy. Active coping operated as a protective factor for the sample population when it came to warding off acculturative stress effects. Conversely, passive coping was not at all a protective factor. The study suggested that coping strategy is a factor of familial influence. So active coping strategy could be a byproduct of heritage ethnic identity retention in the form of familial influence, but passive coping could also be a byproduct of heritage ethnic identity retention if passive coping is learned through familial influence. In this case, traditional ethnic identity exposure could either harm or aid in alleviating acculturative stress effects. More research would be needed. Whether this aspect of heritage ethnic culture retention would be a positive or negative aspect would depend on the coping strategy 
typical of a given culture, if a "typical coping strategy" exists on a scale as large as a cultural scale.

Though the research may be slightly unclear in regards to coping strategies, the study does effectively conclude that acculturative stress is associated with detrimental psychological health effects. The study also suggested that parental and familial social support could help to reduce these acculturative stress effects on mental health, which indicates that heritage culture retention is crucial to combating acculturative stress. This may be true for the sample population that this study examined; however this leads to a potential shortfall in the study.

The population sample was very small and specific in the Crockett et al. (2007) study, which decreases the ability to generalize the results to other diverse populations. Although, many of these research findings fall in line with other studies that have looked at different population groups (Berry, 1997; Berry, 2006; Buriel et al., 1982; Marielena et al., 2005; Lester, 1999). Data that conforms to existing data helps to increase the ability to generalize the research findings across different populations, however the process of acculturation is truly a global phenomenon. Understanding the process of acculturation on a true global scale is integral to better comprehending the relationship between acculturation and the adverse mental health outcomes associated with acculturative stress.

\section{Acculturation: A Global Process}

Acculturation truly is a process set for the global stage, involving millions of individuals and most countries throughout the world (UN Populations Division, 2002). All around the planet, as we continue to churn the melting pot, individuals are finding 
themselves faced with the need to assimilate into dominant culture groups that might be fundamentally different from their own heritage culture group. Berry et al. (2006) lead a global-scale international study to analyze acculturation and adaptation of immigrant youth (ages 13-18) of 26 different cultural backgrounds who were assimilating into 13 different societies around the world. They compared this sample population $(N=5,366)$ with a sample of national youth $(N=2,631)$. The study was guided by three core questions: How do immigrant youth deal with acculturation? How well do they adapt? Are there relationships between how immigrant youth acculturate and how they adapt?

Berry et al. (2006) used cluster analysis to note that immigrant youth were falling primarily into four emerging types of acculturation profiles, which they defined as "integration", "ethnic", "national", and "diffuse" profiles. Those who fell into the integration profile of acculturation identified with both national and ethnic identities and were comfortable in both cultural group settings. Those who fell into the ethnic profile strongly identified with their own ethnic group and endorsed a separation mindset. Those who fell into the national profile identified strongly with their national identity and show very little retention of their ethnic identity. Lastly, those who fell into the diffuse profile held contradictory beliefs about acculturation, endorsing both assimilation and separation. Berry et al. (2006) described the diffuse profile individuals as "wanting to be part of the larger society but lacking the skills and ability to make contacts" (Results section, para. 6). According to this study, these were the four predominant ways that youth acculturate around the world.

The study found that there was a continuum of psychological and sociocultural adaptation; individuals in the integration profile experienced the most optimum 
psychological and sociocultural adaptation, while those who fell into the diffuse profile experienced the worst levels of both psychological and sociocultural adaptation. In the middle were those in the ethnic profile; these individuals experienced adequate psychological adaptation but poor sociocultural adaptation. Slightly behind this were the individuals falling into the national profile, who experienced worse psychological adaptation than the ethnic profile individuals, and "slightly negative sociocultural adaptation" (Berry et al. 2006, Results section, para. 13).

Following the trend established by many other studies of acculturation, the research here suggests that a strong ethnic identity is optimum to mental health, as is evidenced by the fact that immigrants belonging to the ethnic profile tend to fare better than those falling into the national and diffuse profiles. This study adds an important dimension in suggesting that the most favored conditions are to retain a strong heritage ethnic identity while also retaining close ties to the dominant culture group.

This study is crucial to the acculturation discourse in that it was conducted on a global scale. Prior to this, acculturation research was primarily conducted from a macro level analysis with specific ethnic groups assimilating into specific cultures (e.g., Korean immigrants acculturating into North Eastern United States society). As previously stated, one of the difficulties facing acculturation research was the inconsistency of terms and procedures. Berry et al. (2006) helped to change this by introducing an entire coding system in the definition of acculturation profiles. Additionally, because the research was conducted with a large, global population, the ability to safely generalize acculturation tendencies increases. Because cluster analysis was consistent to reveal four distinct acculturation profiles across a substantially sized population sample, this suggests that 
these four acculturation profiles are occurring regardless of potential cultural or ethnic differences and confounds. As such, the theoretical formation of these four acculturation profiles is important and warranted to the global research field around the process of acculturation.

Berry et al. (2006) concluded that the optimum outcome for ethnic minority individuals is the best-of-both-worlds combination of high ethnic identity integration paired with close ties to the national community. The report reads somewhat optimistic in its findings with the declaration that the majority of immigrant youth fall into the integration profile, which was found to be the most successful assimilation style.

However an alternative reading can be gathered from this report. According to the study results, high ethnic identity retention is necessary for increased psychological adaptation. Whether demonstrated in the integration profile group or the ethnic profile group (which was slightly less successful than the integration profile group, but still more successful than the other integration profiles groups), a higher level of ethnic identity retention is a common factor between these two groups aiding in psychological adaptation. The least successful groups, national and diffuse, have decreased ethnic identity retention in common. Because the integration and ethnic groups fare better in this study, the argument could be made that ethnic identity retention is an exceedingly important factor in promoting positive psychological adaptation. Otherwise the national profile group would have fared better than the ethnic profile group. In other words, a decreased ethnic identity seems to have more of an impact than a decreased national identity, as is evidenced by the comparison of the ethnic and national groups in the study. Thus, ethnic identity retention may be the more significant predictor of optimal mental 
health outcomes, beside the marriage of both ethnic identity and national identity connection as found in the most successful integration profile group.

Yet there's still the matter of sociocultural adaptation. In this regard, Berry et al. were surprised to find that:

National orientation did not have a stronger (positive) impact on sociocultural adaptation than ethnic orientation. Ethnic orientation, however, did have an effect on both types of adaptation... we found that the effect on psychological adaptation was stronger than the one on sociocultural adaptation. (Results section, para. 21) The study results indicate that not only does national orientation have a weaker than expected impact on sociocultural adaptation, but the ethnic profile has a much stronger effect on psychological adaptation. This strengthens the argument that there are aspects inherent in an ethnic profile that are preferable compared to a national profile for sociocultural adaptation. This again indicates that ethnic identity retention is a vastly important factor of healthy integration. Berry et al. (2006) addressed the importance of ethnic identity retention, suggesting, "governments should consider providing support for immigrant and ethnocultural community organizations so that cultural loss is limited or prevented, their ethnic identity is promoted, and their way of life is allowed to be maintained and to thrive" (Implications section, para. 3).

However, there is another tier to the data that can be analyzed. Though the pairing of ethnic identity and national identity appears to be most ideal, the optimism in the numbers of population sample may be misplaced. In the Berry et al. (2006) study, there were more immigrants falling into the integration profile than any other profile group, which sounds like a promising statistic given the apparent benefit of this profile 
group. A possible alternative consideration of the data is that the majority of immigrants fell into groups that were not faring well psychologically and/or socioculturally. In fact, the immigrants falling outside of the integration category make up $63.6 \%$ of the entire immigrant sample (ethnic profile $N=975$, national profile $N=810$, diffuse profile $N=973$, total population with complete data $N=4,334)$. This means that over half of the immigrants experienced decreased psychological or sociocultural adaptation in varying degrees during their process of acculturation. Because this study accessed a global and random sample of immigrants, it is fairly safe to generalize these numbers to the total population, which leads to the startling reading that a majority of immigrants attempting to assimilate into dominant cultures are experiencing poor health consequences as a result. This advances the argument that the process of acculturation can lead to less than optimal health outcomes.

Though this study did well to create a code of acculturation and to analyze the acculturation process on a generalizable, global scale, it was not made clear as to the ethnicities of the immigrants who made up the sample population. It is important to study a global process on a global scale. Although because Native American populations experience a disproportionately high amount of mental health issues associated with acculturative stress as well as a disproportionately low representation in acculturation research, it is also important to narrow the research lens and study Native American populations specifically (APA, 2010). It is not clear as to the degree of representation, if any at all, Native American individuals held in the Berry et al. (2006) study. 


\section{Acculturation and Native American Populations}

Research in general with Native American populations is sparse at best likely due to comparatively small population sizes and overall homogeneity throughout the population (APA, 2010). Research of the relationship between acculturation effects and Native American populations has been a fairly new endeavor, as evidenced by the Schiefer and Krahé (2014) study on acculturative stress and Native American psychological well-being.

This study examined a sample population of only Native American individuals. The study used structural equation analysis with both an adolescent and an adult sample group to examine the complex relationships between ethnic identities, integration into "White American society", and psychological well-being (which, in this study, was gauged by self-efficacy and learned helplessness).

As much research has found when it comes to ethnic culture identification and psychological well-being, this study found that the degree of acculturation has a significant relationship when it comes to psychological well-being, specifically that increased levels of heritage ethnic culture identification was positively associated with self-efficacy for both the adult and adolescent sample groups. This suggests that the process of acculturation is perhaps similar in some ways between other ethnic immigrant populations (which have been the focus of most other studies) and Native American populations. Further, this study demonstrated that increased ethnic identity had no effect on learned helplessness for either age group, fortifying the argument that an increase in ethnic identity retention is conducive to better mental health functioning. 
However, the Schiefer and Krahé (2014) study indicates a very interesting and complex relationship between level of integration into White American culture and psychological functioning. Research demonstrated that White American culture integration expressed in the form of behavior typical of White American culture was associated with higher self-efficacy in both samples and with lower learned helplessness in only the adult sample. To further complicate the results, their research indicated that White American culture integration expressed in the form of positive attitudes and sense of belonging were associated with higher learned helplessness in both samples and with lower self-efficacy among adults. This study was able to access these fairly unique findings in that the data was differentiated between White American orientation at the behavioral level (White American behavior) and at the level of psychological closeness and positive evaluation (White American affiliation) under the assumption that White American behavior and White American affiliation were very different constructs.

These results are very interesting in that while they bolster the increasing research demonstrating that increased ethnic identity is associated with better psychological functioning (in this case higher self-efficacy), the results also show that integration into White American culture is a vastly complex system, and perhaps hard to fully understand from a research perspective. The clear implicational differences between White American behavior and White American affiliation on psychological functioning are however, important to analyze. What is the integral element of difference between White American behavior and White American assimilation, and why does behavior create favorable conditions compared to assimilation? 
Perhaps the behavior typical of White American culture can exist without directly affecting a sense of identity. It is possible to participate in the behaviors of and socialize within the dominant culture while also retaining a strong ethnic identity (recall that this "balance of both worlds" was the optimal integration profile established in the Berry et al. (2006) study). Perhaps the ability to successfully and healthily assimilate with the majority culture is more of a process of learning majority group behaviors while retaining one's own ethnic identity, rather than fully immersing in and identifying with the majority group.

Additionally, it is possible that much behavior associated with White American culture is made normative by today's Western culture-dominant global media. Perhaps what was once regarded as specifically White American culture behavior is beginning to shift towards a consideration of "global behavior" as media becomes an increasingly universal and dominant factor in shaping behavior. In this case, participation in White American behavior may take some of the identification factor out of the process of assimilation through behavior adoption. Effectively, much of the construct of White American behavior might be considered largely universal in the modern era, and therefore has virtually no effect on identity.

On the other hand, the construct of White American affiliation seems to address a deeper issue, namely the level of psychological closeness and favorable evaluation of the White American culture (Schiefer \& Krahé, 2014). This cultural evaluation and psychological closeness seems to be a process of much more investment compared to simply learning and adopting the behavior of a culture. It is likely much more difficult to retain an ethnic cultural identity when assimilating through affiliation on a psychological 
and evaluative level. Assimilation on a behavioral level could be a process involving less internal change compared to assimilation on an affiliation level. For example, if one were to transition into a new culture, one could conceivably learn and adopt many of the behaviors of that culture to make socializing a smoother process, all while still retaining a strong personal ethnic identity. This kind of cultural balance might have been the operating force behind the ideal diffuse assimilation profile type established by Berry et al. (2006).

If the process of White American culture assimilation involves cultural evaluation, it is not difficult to conceptualize that cultural evaluation of one's own ethnic culture may take place by comparison as well. When an evaluation between cultures (one's ethnic culture and the White American culture) begins to take place, it could cause tension between one's ethnic culture and the White American culture into which one is attempting to assimilate. It would be enlightening to continue the Schiefer and Krahé (2014) study to analyze the Native American individual's level of ethnic identity retention while analyzing their degree of White American affiliation. If increases in White American affiliation were associated with decreases in ethnic identity retention, then the associated harmful effects on psychological functioning (in the case of this study, increased learned helplessness and decreased self-efficacy) could theoretically be due to either an increase in White American affiliation, or a decrease in ethnic identity retention, or some degree of interplay between the two constructs. Regardless, if ethnic identity decreases were associated with White American affiliation increases, it would suggest that ethnic identity loss is detrimental to healthy psychological functioning to 
some extent. This would further fortify the argument that ethnic identity is critical to optimal psychological functioning.

Given that the cross-sectional nature of the data detailed in the Schiefer and Krahé (2014) study precludes any causal inferences, it is difficult to determine whether the process of assimilation through White American affiliation in itself is related to ineffectual psychological functioning, or if White American affiliation causes a decrease in ethnic identity retention, which then negatively affects psychological functioning. There is always the possibility of the two constructs working together to affect psychological functioning as well. At this point, there is insufficient data in the study to determine such causalities, and more research is needed in this tragically underrepresented field of research concerning the process of acculturation within Native American populations.

Because research with Native American populations and the process of acculturation is seldom represented in the field, the available pool of research to choose from is shallow at best. However, Lester (1999) has been referenced and cited by innumerable writers in the field for his research on Native American populations, acculturative stress and suicide rates.

Lester (1999) conducted large-scale research with 18 different Native American tribes (Apache (Mescalero, San Carlos, and White Mountain), Arapahoe, Cherokee, Cheyenne, Navajo, Papago, Pima, Pueblo (Hopi, Isleta, Jemez, Laguna, San Felipe, Santo Domingo, and Zuni), Shoshoni, and Sioux) to analyze the relationship between suicide rate and level of integration into "white society". Acculturative stress was coded over two levels (high and low), and traditional integration was coded over three levels (high, medium and low). 
The point-biserial correlation indicated significant relationships between level of assimilation into white society, traditional integration, and suicide rate. In this study, Lester (1999) found that assimilation into "white society" was positively correlated with acculturative stress. Further, the study pinpointed that suicide rate for the entire 18-tribe sample population was positively correlated with level of acculturative stress. That is, as acculturative stress increased, so too did the corresponding rate of suicide. Conversely, the study found that traditional culture integration was negatively associated with suicide rate across the entire 18-tribe sample population. This means that as Native American individuals were further integrated into their traditional heritage culture, the corresponding rate of suicide was lower as a result. In summary, Lester (1999) claimed that suicide rate was positively associated in Native American tribes with increased "white society" assimilation, and thus increased acculturative stress, while suicide rate was negatively associated with tribes wherein traditional heritage culture integration was higher.

This study generated many crucial advances in the field of research dealing with Native American populations and the adverse effects of acculturative stress. First, an important aspect of the research is the population sample. It is all too easy to categorize all Native American people under the catchall of "Native Americans", when there is tremendous diversity between different members of different tribes. It is dangerously simple to conduct a study on a narrow population of Native American people and assume that all Native American individuals fall neatly into line within the research assumptions. Lester (1999) conducted the study of suicide rate and acculturative stress over a large scale of diverse tribes. In this light, the findings indicate not only that suicide rate and 
acculturative stress have a dangerous association, but also that this association is a widespread problem across many tribes. This aids in the generalizability of the results, indicating that acculturative stress is likely something that can affect Native American individuals regardless of any cultural differences attributed to tribal diversities.

Aside from addressing issues of cultural differences between tribes, Lester (1999) achieved an insightful look into the functioning of a rarely researched construct within a rarely researched group. Extant research with regards to acculturative stress has largely evaded Native American populations. As previously mentioned, research with Native American populations is difficult to conduct for many reasons, such as small population size, heterogeneity of the population, and location (APA, 2010). However because Native American populations experience the highest rate of suicide and a disproportionate amount of mental health issues associated with acculturative stress, it is all the more critical that research is conducted with the construct of acculturative stress in Native American populations (APA, 2010). To begin treating the disproportionate mental health issues associated with acculturative stress in Native American populations, it is necessary to understand the functioning of the interplay between the people and acculturative stress. Lester (1999) demonstrated that, as existing research has done for other ethnic groups, acculturative stress and level of traditional integration are significant contributors to the state of overall psychological well-being.

Lastly, this study goes one step further than many other studies in its analysis of the relationship between adverse mental health effects and acculturative stress. Many other studies sought to explore the relationship between acculturative stress, dominant culture integration, and adverse mental health effects, while the Lester (1999) study also 
analyzed the relationship between traditional culture integration and positive mental heath effects. Establishing the negative relationship between acculturative stress, adverse mental health outcomes and traditional culture integration alongside the positive relationship between acculturative stress, adverse mental health outcomes and dominant culture integration paints a more dynamic picture of the construct of mental health and the process of acculturation.

These results, just as the results of other studies reviewed up to this point, suggest that the process of acculturation can potentially result in harmful mental health outcomes. This study suggests that, for Native American populations, the process of acculturating into dominant Western culture can result in unfavorable mental health functioning and behavior (in this case, increased rate of suicide) while increasing traditional Native American culture integration can not only mitigate but also begin to entirely reverse this precarious trend. Given that further integration into traditional Native American culture can reverse acculturative stress effects, it is feasible that perhaps there are protective factors inherent in the very fabric of traditional Native American culture itself.

The Resiliency of the Native American People

Many of the previous examples of literature categorized factors of moderating the potentially negative byproducts of the acculturation process, such as social support, coping strategy, identification with majority group behaviors, assimilation style, and especially heritage ethnic identity retention. Bradway (2011) brought to the table one more highly important combative strategy with his discussion of Native American resiliency. 
Bradway (2011) implemented a quantitative between-subjects survey design to study resiliency in Native American populations. Surveys were sent to Native American individuals living in the Fort Belknap Reservation in Blaine and Phillips counties in Montana. Bradway (2011) constructed his research design around a vastly expansive outline of the research field surrounding resiliency, psychological functioning, and Native American populations. Following a documentation of the research field, Bradway (2011) used descriptive statistics to illustrate that Native American cultures are in fact highly resilient, and that Native American culture retention is a significant factor in developing resilience.

In his study, Bradway (2011) determined that the resiliency found as a byproduct of Native American culture is a form of profoundly robust resilience, with increases in trauma showing only a miniscule effect in overall resilience. This is a largely unique cultural factor of Native American resilience. The research suggests that Native American resiliency is a specialized and highly vigorous form of resiliency. In regards to this specialized construct of resiliency, Bradway (2011) stated:

There seems to run in the American Indian culture a strong undercurrent of the ability to deal with any hardship. This ability to make trauma negligible might be a dynamic of the stoic "warrior" culture that permeates this population. It is a cultural imperative that comes from countless eons of carving survival out of an often-hostile environment and one that seems to continue unspoken in this population. (p. 163)

Given that this specialized form of resilience appears to be a byproduct of Native American culture, this further fortifies the argument that decreased heritage culture 
retention and exposure may be linked to increased acculturative stress in Native American populations. For if resiliency is a byproduct of Native American culture, then decreased identification with and exposure to such a culture could conceivably result in a decrease in resiliency. Conversely, those who strongly identify with and participate in such a culture would likely benefit from the byproduct of an increased and especially robust form of resiliency. Especially because the resilience of Native American culture appears to be uniquely vigorous, it is not difficult to conceive that Native American individuals could better combat the pressures of acculturative stress with the added benefits of both increased specialized resiliency, and the reduction of the aforementioned processes by which acculturation can cause acculturative stress (incompatible cultural values, language difficulties, familial tension, lack of a feeling of belonging etc.) (Gil, 1994; Miranda, 2006).

This research, as all the research presented thus far, furthers the argument that a greater identification with and retention of one's heritage ethnic identity is indicative of better psychological functioning and mental health. This has been shown to be true on a global scale with various immigrant populations and varied dominant cultures, and on a smaller scale for Native American populations as well.

The Bradway (2011) study is important in that it provides well-documented empirical advocacy for supporting programs that enrich Native American culture. Bradway (2011) suggested that programs already in existence such as "indigenous language training, cultural support classes in primary and secondary school, and college cultural studies classes" (p. 165) should be funded and supported in order to enrich ethnic cultural retention, increase resiliency, and thereby ameliorate overall psychological 
health. By promoting and empowering ethnic cultural retention, resilience can be maximized and utilized to combat the negative effects of acculturative stress, thereby beginning to address many of the associated mental health issues that are so unfortunately rampant in numerous Native American populations.

Once again, research demonstrates that retention of ethnic identity is a vastly important aspect in mitigating the effects of acculturative stress, and increasing the quality of mental health and psychological functioning. The Bradway (2011) study further suggested that ethnic culture retention is especially helpful for Native American populations with the added benefit of their culturally-formed specialized resiliency.

\section{En Route to a Culture-Focused Music Therapy Program}

Because Native American culture appears to include this specialized form of resilience, Native American individuals might experience an exceptional benefit from increasing their ethnic identity exposure and retention. This specialized resiliency is a factor of Native American culture that could not only help in attenuating the effects of acculturative stress, but it could also operate as a factor contributing to the ease of the process of increasing one's ethnic cultural identity. As mentioned previously, the process of increasing Native American ethnic culture exposure can be difficult given the history of persecution and forced assimilation facing Native American individuals. In other words, the trauma of the past can be a factor repelling one away from Native American ethnic identity exposure. However, in acquiring a newfound specialized resiliency, the initial difficulty of increasing identification into Native American culture might eventually be alleviated to some degree. This would create a cycle of increased ethnic 
culture powered by a byproduct (the specialized resiliency) of increasing ethnic culture identification. Simply put, it is a process of using the strengths of the Native American culture to increase ethnic identity retention and exposure. Programs that seek to increase Native American cultural exposure and retention (such as those referenced above in the Bradway (2011) study) might benefit from structuring the program design on the specialized strengths of the culture.

This is where music comes in. Recall that music is one of the most innate and quintessential aspects of the human experience. As such, the process of creating and engaging with music is largely inextricable from culture itself. Because every culture (at least within the last 50,000 years) has this innate link to music, a culture-focused music therapy program would utilize a human construct that is close to the very core of humanity and culture (Wallin, 2001). As acculturative stress is consequent on cultural strain, a program that seeks to affect change on a cultural level (i.e. reintegration into heritage culture) could benefit from using a construct as culturally ingrained as music. Such a program could help alleviate some of the negative psychological side effects of acculturative stress. This might be especially true for Native American populations given their historically intimate cultural links with music.

Though music has close ties with culture, it must also be an effective means of therapeutic intervention to fully address acculturative stress. Culture is half of the aspect of battling acculturative stress; the remainder is in focusing on mental health. Music and its cultural bonds are crucial for cultural empowerment, but music has to be effective on a mental health level if it is to be effectively utilized in a program targeting acculturative stress. 
The Therapeutic Power of Music

In their compilation of years of research, Rickard and McFerran (2012) provided a rich analysis of music and its effect on mental health and well-being across the human lifespan in many different populations while studying through numerous disciplinary lenses. Of particular relevance are the sections dealing with music and mental illness, and music and various forms of mental health and well-being.

In a quantitative clinical study on the effects of music on rehabilitation and treatment of chronic schizophrenic patients, Pavlicevic, Trevarthen, and Duncan, (1994) conducted a matched sample trial of 41 patients diagnosed with severe schizophrenic (20 in the control group and 21 in the treatment group). In addition to standard care, both groups received music therapy sessions over the course of a ten-week study. The design of this particular music therapy program was an improvisational music therapy program. In such a program, participants explore free musical expression on tuned and untuned percussion instruments that typically require no formal music training, i.e. xylophones or glockenspiels. Sessions typically take place in one-on-one client-therapist settings, but are also conducted in group therapy sessions as necessary (Rickard \& McFerran, 2012).

In the study, the control group received two music therapy sessions, one session at the beginning and one at the end of the study. The treatment group received ten music therapy sessions, one per every week of the study. Changes in symptoms were monitored using the Brief Psychiatric Rating Scale (BPRS).

At the end of the ten-week study, results indicated that there existed a statistically significant improvement of schizophrenic symptoms in the treatment group compared to 
the control group. The study results indicated that an increased engagement with music could positively affect mental health symptoms for individuals with severe schizophrenia.

These results explicate a powerful relation between music and mental illness. Music appears to have a therapeutic quality in its interaction with mental health. As music illustrates that it has the ability to affect positive change in cases of severe mental illness, it is demonstrative of the therapeutic ability of music with mental health. If music effectively influences the relationship between severe mental illness and mental health, then perhaps the same competency of musical therapeutic intervention can be applied to many different mental health issues, such as those associated with acculturative stress.

Grocke et al. (2009) examined this relationship between music and different indicators of mental health. Their research was both qualitative and quantitative in nature, operating under the theory that a combination of qualitative and quantitative data provides a better understanding of the research. Grocke et al. (2009) designed their study as a concurrent-nested research model (where data is gathered at the same time and analyses are executed concurrently) with the hypothesis that engaging in music therapy would positively impact quality of life, social anxiety, mental illness symptoms and overall well-being in patients with severe mental illness.

The study worked with 17 individuals diagnosed with diverse mental illnesses. Participants engaged in one-hour long music therapy sessions for eight weeks. In this study, the music therapy sessions comprised elements of singing and songwriting. Participants began sessions by singing preferred and familiar songs, followed by facilitated group songwriting. Individuals worked as a group under the guidance of the music therapist to determine song theme, write lyrics and sections (choruses, verses, etc.) 
and determine music elements such as genre, melodic shape, song form, and harmonic progressions. At the end of the eight-week study, participants had the opportunity to record and distribute their song.

Data was collected in the form of participant interview and self-report surveys. Further, the effect on quality of life, social anxiety and mental health symptoms were measured using the World Health Organization Quality of Life Brief (WHOQoLBREF), the Social Interaction Anxiety Scale (SIAS) and the Brief Symptom Inventory (BSI).

Based on their data, Grocke et al. (2009) concluded that quality of life, satisfaction with overall health, social support, physical pain, and social interaction all established statistically significant relationships with engagement in music therapy, demonstrating positive improvement in each of these categories. Further, interviews and self-report surveys indicated that participants benefited from the entire process, suggesting that, in addition to being a healing process, the music therapy process was both pleasurable and relaxing for individuals diagnosed with mental illness.

These results indicate that music can positively impact individuals for many different forms of diagnosable mental illness. If music can be an effective therapeutic intervention for a variety of diagnosable mental illnesses, then perhaps music can be a successful therapeutic intervention for anyone, with or without diagnosable mental illnesses, who are experiencing lower states of psychological functioning. Psychological functioning is a multi-faceted, complex system that is relevant to all people, and healthy psychological functioning is conducive to overall well-being. Because the potential target of impact for music therapy is apparently wide and diverse, this bodes well for the 
theoretical use of music therapy to address the myriad adverse mental health effects of acculturative stress.

Also studying music as a therapeutic intervention, Keon (2013) discussed how music could be used as a therapeutic measure to bolster healthy psychological functioning. In this study, healthy psychological functioning is measured in level of "psychological flexibility", a concept that is gaining more attention across multiple disciplines within the research field. Psychological flexibility is a crucial aspect of psychological health. A lack of psychological flexibility can lead individuals to experience an inability to adapt psychologically, to change emotional sets, or to regulate emotion or attention. Without psychological flexibility, one is essentially stuck in a state of attention or emotion associated with some trigger, resulting in a constant state of dejection, anger, or depression (Hinton, 2008). In other words, for individuals who are lacking in psychological flexibility, a single circumstance (for example, perhaps being caught between two cultures and feeling alienated from both) causes a constant fixation on the circumstance, which results in poor mental health outcomes.

Keon (2013) described the relation between psychological flexibility and music, stating, "psychological flexibility is viewed as being important for health within diverse cultures and it is promoted through multiple means, music being the most understudied and perhaps the most powerful" (p. 175). If music is perhaps the most powerful means of promotion of psychological flexibility in diverse cultures, it is deplorable that music is among the "most understudied" means of promoting psychological flexibility.

To add to the scarce research involving music and psychological flexibility, Koen (2013) designed a case study including in-depth participant-observation field research to 
analyze if maddoh (which translates literally to, "praise", a form of sung poetry music found in many Eastern cultures, such as Persian, Arabic and Turkish) was a successful primer of psychological flexibility. The population of focus was not selected on the basis of mental illness prevalence.

In results of the study, Koen (2013) concluded that maddoh music was in fact shown to be a successful primer of psychological flexibility, citing the form and structure of the music and its interaction with energy and individual spirituality. Interestingly, Koen (2013) found that the very construction of maddoh music, such as the song form, distinctive rhythm, sonic structures, and spiritual and mystical meanings of maddoh, could actually drive an individual from a state of psychological inflexibility to a state of psychological flexibility. Research has shown that music can interact with the mind and body in similarly curious ways (Sacks, 2008). Research also demonstrates that cultures use music to promote a state of psychological flexibility by enacting cognitive action and shifts (Hinton, 2008). Koen states "the experience of the music is one that can create a psychological, emotional, spiritual, or bodily shift for participants" (p. 194). It is this shift promoted through music that has been shown to encourage a state of psychological flexibility.

An important research component of the Koen (2013) study is that it analyzed music and its relationship to mental health among individuals outside of clinical mental illness diagnosis. As the Grocke et al. (2009) study and the Pavlicevic et al. (1994) study have corroborated, music can have positive healing effects for individuals with diagnosed mental illness. However, given the population analyzed in the Koen (2013) study, the results indicate that individuals need not be in the throes of a severe diagnosed mental 
illness to benefit from the therapeutic powers of music. Unlike other forms of mental health intervention, such as medication, music engagement appears to be a safe and effective process conducive to healthy mental health and psychological functioning for individuals with and without clinical mental health diagnoses.

Additionally, this study provides an interesting perspective of diverse forms of music being effectively utilized to promote psychological health. Many kinds of music from various cultures, whether classical, jazz, contemporary, maddoh or nearly anything in-between, have been shown to interact with the mind and the body in fascinating ways (Grocke et al. 2009; Koen, 2013; Sacks, 2008; Rickard \& McFerran, 2012). This study demonstrates yet another variety of culturally specific music positively impacting psychological health via simple engagement with that form of music. This helps to increase generalizability that music as an entire entity has a positive therapeutic influence. If diverse genres of music can elicit diverse healing effects, then music in itself, regardless of genre might be a healing therapeutic intervention. To this effect, Koen (2013) states,

Certainly, the potential for music to effect health changes, either through the dynamic indicated by psychological flexibility, or perhaps framed by other concepts or practices, is not limited to one genre of music or one culture. Indeed, diverse musical forms and practices can promote flexibility to engender a state from which health changes or healing can arise. (p. 194)

Research with diverse forms of music appears to indicate that this is true; that music is in and of itself a therapeutic force that can be used for healing. If this is accurate, then 
Native American music should follow suit of other forms of music and promote psychological healing as well.

\section{Music and Native American Culture}

According to Hamill (2009), much of music escapes traditional science as it often encroaches upon the realm of spirituality. This is true for many cultures throughout the world, including Native American cultures. In part of his examination of the healing power of Native American music, Hamill (2009) explored Native American music in terms of spiritual power and healing power. Using primarily case studies and personal experiences, the report detailed the functioning of music within Native American culture.

In the tradition of Native American culture, spirituality occupied a tremendously important role in Native American life, and healing and well-being were achieved in terms of energy and power. Music is one of the central most aspects of this spirituality and power that is so central to Native American culture. In fact, according to the Hamill (2009) study, Native American culture recounts that much traditional Native American music was composed outside of the individual; the music was so meaningful and important that mortal men were not the composers, but rather spirits were the composers.

There have been many case studies and personal account of song "coming to" an individual in Native American culture, when an individual is confronted with spiritual energy and a song the individual has never heard or sang before flows from them in a process of "simultaneous embodiment and enactment" (Hamill, 2009, p. 68). In Native American culture, this process is often conceptualized as a collaborative process between human beings and the spirits of ancestors. In this light, music acts as a sort of 
cultural/spiritual link between people of Native American heritage. In the Hamill (2009) study, there are many case studies (far too many to even begin to detail) that outline the use of transmission of spiritual energy and power through the sole use of sound and music, connecting individuals with their own people and ancestors through music. In Native American culture, music serves as a vessel of healing (mental, physical, and/or spiritual healing) through spiritual power and energy. This is a testament to the profound cultural, spiritual and healing significance of music within traditional Native American culture.

Though music plays a paramount role in the landscape of Native American culture and in the process of Native American healing, music is still something that is rarely studied in this context. Hamill (2009) touched upon this, stating,

As a central embodiment of spiritual power, song has more often than not been overlooked in studies related to indigenous spiritual practice in North America... Scholars have acknowledged it as important, perhaps even integral, but inquiry often ends there" (p. 67)

Perhaps because music is an abstract construct that often approaches the realm of spirituality and immeasurable experience, traditional science and observation has been unable or reluctant to touch upon music as a vessel of cultural healing. Though much of it may be disprovable or beyond hard science, many centuries worth of experience and feeling of an entire people is an entirely real entity, and music must be taken for what it is; a truly significant cultural aspect of traditional Native American heritage, one that connects people, heals people, and carries the energy and power of the people through to younger generations. 
Another study that examines music in the context of Native American culture, Wiand (2004) demonstrated how music in Native American culture could help promote healing in specific clinical settings. Where Hamill (2009) analyzed Native American music in terms of complex spirituality and energy, Wiand (2004) focused on a long history of Native American music as a healing force, leading up to a clinical-based experiment centered on addressing the psychological side effects of psychological Dissociative Disorder with measurable scientific data.

In the study, Wiand (2004) discussed that Indigenous and ancient cultures have been known to experience music in a unique fashion. Native American culture has historically viewed sound and music as a sacred entity, and the healing process of music is ultimately about bringing wholeness back to the individual. Music is a deeply rooted sacred process; in fact, most Native American tradition recounts that, "this world was sung into existence” (p. 38). As traditional Native American history relates, the very creation of the world, the entire physical space of life's existence, was created through music. In fact, according to Native American tradition, everything in the universe is created from sacred sounds, and everything in the universe has its own song. Because everything was created from sound, and because everything is itself sound, it can be said that sound and music impacts everything. In a sense, sound and music are everything in Native American traditional culture. This speaks volumes of the substantial position music holds in the cultural history and understanding of Native American tradition. In the Wiand (2004) study, the focus was on the sounds and songs of the Native American flute. 
According to the Wiand (2004) study, legend tells that "the flute is as old as the world" (p. 38), and it is an instrument of significant and powerful healing. The Native American flute is an integral part of traditional Native American music, and the sound is a sacred sound that promotes healing and wholeness. Given this history, Wiand (2004) suggested that Native American flute music could directly and indirectly affect Dissociative Disorders in a therapeutically positive manner.

To test this theory, Wiand (2004) divided participants into two primary groups, individuals with Dissociative Disorder, and a control group. Participants were then assigned to listen to either Native American flute music or placebo music. The experiment was designed to measure levels of anxiety and interconnectedness amongst participants. Lower levels of anxiety and higher levels of interconnectedness are conducive to healthy psychological functioning. Conversely, high anxiety and low interconnectedness levels are indicative of Dissociative Disorder and unhealthy psychological functioning. The piece of music played on the Native American flute was "Ancient Spirits", by Aluna, a piece that has reportedly been known to have "shamanistic characteristics" (Wiand, 2004, p. 102).

Results of the study showed that listening to Native American flute music lead to significantly greater decreases in anxiety when compared to listening to placebo music for both the Dissociative Disorder group and the control group. Additionally, research demonstrated that listening to Native American flute music directly led to a significantly greater increase in perception in interconnectedness for both the Dissociative Disorder group and the control group. 
These results are important in that they demonstrate the potential therapeutic healing power of Native American music in particular. Music in general has been shown to be an effective agent of healing for both mental and physical afflictions (Grocke et al. 2009; Sacks, 2008; Rickard \& McFerran, 2012). However this study illustrates that Native American music specifically might be an especially potent form of healing when compared to other forms of music. To further this theory, Wiand (2004) took measures to analyze whether the healing effect of the music had anything to do with simple enjoyment of the music. In the study, participants were asked about their feelings of the music played after listening. The results were fairly evenly spread; some people enjoyed the Native American flute music and others did not. What is interesting about this feature of the study is that regardless of personal opinion of the music, Native American flute music was still an effective means of reducing anxiety and increasing connectedness. This suggests that, like maddoh music in the Koen (2013) study, there is something inherent in the very construct of the Native American flute music that was healing. Further, some participants thoroughly enjoyed the placebo music, however still, the Native American music promoted more effective healing. This indicates that the healing effect is apparently robust enough that one does not have to necessarily enjoy the Native American flute music for it to have a healing impact.

Evidently Native American music has a specialized construction of sound that lends towards especially effective healing. Most of the participants in the Wiand (2004) study indicated that the Native American flute music was "peaceful", or "soothing". Those who did not enjoy the Native American music reported that the music was peaceful or soothing as well. 
Traditional Native American culture has been healing its people through the use of music for centuries (Wiand, 2004). Perhaps the reason this was and still continues to be an active custom of healing is that the process is so effective. Because Native American music appears to be especially effective in terms of its healing ability, logic dictates that it would serve as a highly useful musical therapeutic intervention. Additionally, because music plays a significant role in traditional Native American culture, the music could reintegrate Native American individuals within their heritage culture. In this method, using Native American music as a therapeutic intervention to address acculturative stress could heal on multiple levels: Native American music could operate independently based on the merits of its apparent healing ability, for example, engaging with Native American music might help alleviate some of the effects of acculturative stress (such as anxiety, depression, and/or feeling disconnected and isolated) just through the process of music engagement itself. However, because Native American music is so deeply ingrained and entwined with traditional Native American culture, engagement with Native American music might also help in reintegrating and empowering Native American individuals with their heritage culture.

The concept of reintegrating and increasing exposure into one's traditional ethnic culture is a crucial advance in combating acculturative stress. These concepts of heritage cultural integration and music as a therapeutic healing force seem to logically fit together and compliment each other. It is for these reasons that combining Native American music with traditional culture integration to address acculturative stress in Native American populations would theoretically be an ideal and effective endeavor. This 
hypothetical marriage of concepts is the backbone of the proposed culture-focused music therapy program to be utilized within Native American populations.

Such a program is at this point merely theoretical, but the research presented thus far supports the potential efficacy and the need of the proposed culture-focused music therapy program to mitigate acculturative stress in Native American populations. What follows is the theoretical framework outlining the possible directions of initial research design, program design and implementation, and implications for future research.

\section{Hypothetical Program Design and Implementation}

Before the implementation of a culture-focused music therapy program, details of the actual design of the culture-focused music therapy program would need to be addressed, such as the construction and duration of the therapy program, location of the therapy program, staffing, training, recruiting, and funding. However before this, measures would need to be taken to insure that there is both a need and a desire for such a program in Native American populations.

The Need and Desire

Given the current landscape of mental health problems related to acculturative stress affecting Native Americans, and the potential benefits of using a combination of traditional Native American culture integration and music therapy, the need for such a program is evident. The extant research and literature, as previously outlined, suggests 
that the processes of acculturation and acculturative stress are related to many adverse mental health issues affecting Native American populations in disproportionate amounts.

Further, existing research suggests that increasing heritage cultural identity exposure can mitigate the effects of acculturative stress. Aspects of heritage culture, appears especially Native American culture (specialized resiliency), can greatly impact mental health issues associated with acculturative stress. It makes sense to utilize the strengths and core aspects of culture to affect cultural change. One such innate aspect of human culture is the construct of music. This is an especially prominent cultural feature in most traditional Native American cultures, as music is an integral and inextricable piece of most aspects in life, spirituality and the universe as a whole. While perhaps these cultural aspects of music could work to increase and empower Native American individuals in their traditional culture identity, music is additionally a powerful therapeutic force in and of itself. These two aspects, traditional heritage culture retention and exposure and music as a therapeutic intervention, can work together to impede the adverse effects of acculturative stress.

The disproportionate mental health issues affecting Native American populations, paired with the theoretical ideal fit of a culture-focused music therapy program speaks to the need and potential efficacy of the implementation of such a program. On paper and in theory, the need for implementation of a culture-focused music therapy program for Native American population seems more than logically justified, and the potential for the program's efficacy appears entirely cogent.

Yet regardless of any theoretical musing, the entire concept is dependant on whether or not there is a desire for such a program. Through informal discussions with 
members of the Native American community, it has been made profoundly clear that there is an interest in a culture-focused music therapy program as a therapeutic intervention for healing within Native American communities. To better understand the level of desire, it would be beneficial to conduct formal and expansive surveys within Native American communities. This would be a necessary step for future research to be taken before the actual program implementation. Of course, the design of the program itself must also precede the implementation of a culture-focused music therapy program.

\section{Schematics of a Culture-focused Music Therapy Program}

The need for a culture-focused music therapy program has been established, and once the desire for a culture-focused music therapy program has been warranted, the design of the actual program must begin to take place. As far as the current research field is concerned, there is no existing blueprint of a culture-focused music therapy program. There is an apparent hole in the field when it comes to the utilization of music therapy to increase heritage culture identity exposure to combat the effects of acculturative stress. As such, the theoretical design of the program breaks into new territory, and there is not much of an existing reference point from which to begin construction of the program.

Existing music therapy programs are diverse in composition, and utilize methods that have a proven record of success in treating mental health (Rickard \& McFerran, 2012). There are elements from these programs that would serve to benefit the proposed culture-focused music therapy program. Consequently, the best reference point from which to begin the program design is the current construct of music therapy programs. 
Music therapy offers a range of employable methods and settings of practice. The methods used and the type of setting (whether group sessions or individuals sessions) are typically determined relative to an initial assessment of the client or clients (Rickard \& McFerran, 2012). This would likely be the ideal methodology for the culture-focused music therapy program. Although, the culture-focused music therapy program would ideally impact people on a group level, (i.e., strengthening tribal groups of Native American populations) to strengthen community ties to the culture of the people. Yet the goal is for participants to benefit from the healing powers of Native American music, while learning about and engaging with their traditional Native American heritage culture to empower their own Native American cultural identity. Though it would be ideal to strengthen cultural ties across entire groups of Native American populations, it would also be counterproductive if initial assessments proved that some participants would experience greater benefit in a one-on-one culture-focused music therapy setting.

Whether a group setting or an individualized setting, the proposed program would have to be customized to meet the specific needs of the population. Part of this customization would include the decision of which music therapy methods to employ, however some music therapy methods are quintessential in the majority of music therapy practices.

\section{Music Therapy Methods}

Methods used in music therapy are also typically dependent upon initial assessment of client or clients; however, there are some fundamental methods that are basically universal amongst music therapy practices. These methods include 
instrumental improvisation, singing, and receptive activities such as listening to, relaxing to and analyzing music (Rickard \& McFerran, 2012). Because these cornerstone music therapy methods have shown themselves to be steadfast amongst practicing music therapists, their inclusion into the culture-focused music therapy program would be ideal. Each of these individual methods could have a logical place in a Native American culture-focused music therapy program.

First, receptive activities in music therapy, such as listening to, relaxing to, and analyzing music, are related to the healing powers of music itself as previously outlined. These receptive activities could work to heal some of the damage that acculturative stress has caused for participants. For example, listening to and relaxing to Native American music (recall that Native American flute music was found to be especially effective) could help to mitigate anxiety and stress related to acculturative stress.

Additionally, receptive activities such as analyzing music could help to strengthen cultural knowledge and identity. The culture-focused music therapy program would ideally employ an emphasis on cultural education through music in addition to healing through music. If the therapist or facilitator of the culture-focused music therapy program were educating participants as to the historical, cultural, social and/or emotional circumstances surrounding the piece of music being analyzed, perhaps participants could begin to understand and feel connected to these circumstances of their heritage culture. In analyzing a particular piece of music, participants could feel a connection to their culture and their ancestors once they begin to understand the historical, cultural, social and/or emotional circumstances influencing the music. This could function to empower 
and increase awareness of heritage culture identity, which of course operates to assuage the effects of acculturative stress.

Another universal music therapy method that could operate effectively in a Native American culture-focused music therapy program is the practice of instrumental improvisation. As mentioned previously, instrumental improvisation in the context of music therapy is usually conducted with tuned and non-tuned percussive instruments (Rickard \& McFerran, 2012). It just so happens that one of the single most significant instruments in traditional Native American music is the drum. Drums hold such a significant place in Native American music that tribes often establish strict protocol for playing the drum, and the drum is considered by many tribes to be the heartbeat of Mother Earth. In traditional Native American culture, many tribes consider the drum and the act of drumming to be a means of communication with the supernatural (Wishart, 2011).

The goal of instrumental improvisation is not to refine musicianship (clients are typically untrained in music), but rather to create a dialogue between music therapist and client(s) and between multiple clients if practiced in a group setting. The dialogue includes decisions of how to create the improvisation (i.e., who will do what on which instruments, the theme of the improvisation) and what the improvisation means (i.e., the role of the participant(s) in the resulting music and emotions influencing the musical exploration, etc.) (Rickard \& McFerran, 2012).

Because instrumental improvisation is typically practiced on percussion instruments, this method could be underscored by a strong educational aspect on the significance of the drum in traditional Native American culture. Because the drum has 
remarkable emotional and spiritual positions in traditional Native American culture, participants could learn about and engage with these spiritual and emotional aspects of their own culture. This could help to integrate Native American individuals within their traditional heritage culture, all while simultaneously participating in the healing process of creating and engaging with music.

Lastly, the universal music therapy method of singing could fit well within the context of a Native American culture-focused music therapy program. Singing familiar and preferred songs is the mainstay across all client groups and age ranges in contemporary music therapy practice. In addition to the healing powers of simply becoming involved with music, singing is particularly effective in engaging both individuals and groups in orienting participants towards a here-and-now experience, and in bringing groups together (Rickard \& McFerran, 2012). Perhaps because singing helps to increase group cohesion, this is one of the reasons that group unison singing and chanting has long been an integral aspect of traditional Native American culture. Further, singing is a very spiritual cultural form of music in traditional Native American culture (Wishart, 2011). Increasing group cohesion could be beneficial for promoting closeness between individuals coming under unity of their heritage culture.

While promoting closeness between group members, singing could also act as a vessel of cultural education and empowerment. Native American music is deeply ingrained with spiritual and cultural aspects inherent in the construction of the music itself. In understanding the spiritual implications of traditional Native American singing, participants might begin to feel an understanding or closeness to their traditional heritage culture through the use of music, spirituality, and group cohesion. 
Further, research indicates that singing can help to address the gulf between finding meaning in the world, and feelings of isolation consequent on being out of touch (Bohnert, 1999). This is significant to the design of a culture-focused music therapy program addressing acculturative stress. Recall that one of the negative effects of acculturative stress and the process of acculturation is the feeling of isolation. This means that the method of singing could provide the healing benefit of simple music engagement, and also promote group cohesion, increase cultural identity connection through cultural and spiritual understanding, and assist in potentially mitigating feelings of isolation associated with acculturative stress.

The current universal methods of music therapy are universal for a reason, and these universal methods would be entirely efficacious to the design of a Native American culture-focused music therapy program. The theme for this culture-focused music therapy program is to educate and empower Native American individuals of their heritage culture through the use of music, while simultaneously healing the wounds of acculturative stress through music engagement. This means that while music therapy methods are a central aspect to the program, so too are cultural educational and empowerment methods. Each of the above detailed music therapy methods would be underscored with a theme of cultural education and empowerment through learning about and engaging with traditional culture music. Additional cultural education and empowerment methods can be derived from the work of Soderholm (2001). 


\section{Methods of Cultural Education and Empowerment}

Soderholm (2001) designed a course entitled "Music of the People- Native American Music", with the goal of educating individuals of the cultural and spiritual aspects of music within Native American culture. The course is a six-lesson curriculum intended for $3^{\text {rd }}$ grade students, however there are elements of the course that would benefit any individuals seeking to learn more about Native American culture and music.

The course includes performance attributes, such as learning to play instruments, sing in the style of Native American music, and dance in the style of Native American music, all while educating participants of the cultural and spiritual significance of the music and the performance. Additionally, participants learn vocabulary and the history of cultural aspects through music, as well as how the music relates to historical and cultural traditions in Native American heritage. The course design also includes additional complimentary sources for teachers and students, homework sheets in the appendices, and a step-by-step detailed plan for every lesson outline. Additionally, this course includes a curriculum component in designing and building Native American instruments, such as rattles.

These are all course elements that would make an exemplary fit in a culturefocused music therapy program. The program emphasizes cultural learning through a musical lens, and these course components would be an ideal inspiration point to build a design of cultural learning to pair with methods of standard music therapy. This would ideally create a program bolstered by both music participation and cultural learning and empowerment, which is the ultimate goal of the proposed culture-focused music therapy program. 
The Nuts and Bolts

Of course the design of the program itself is of the utmost importance to the implementation of the proposed culture-focused music therapy program. However, there are operational details of the program that would need to be addressed before implementation into a real world setting, such as funding, training, recruitment of participants, and location and duration of the program.

A therapeutic intervention program rarely, if ever, requires no funding whatsoever to operate. Given this fact, funding is an important step in bringing the proposed culturefocused music therapy program to fruition. This program would require training, staffing, location, and essential items such as instruments and means to play recorded music. These are all items that would likely require funding. This author is wholly untrained in long term cost models and nonprofit funding details, so the first and most important step in funding would be either exhaustive research beyond the scope of this project, or partnering with individuals well equipped to handle the monetary demands of implementing a nonprofit program. Though steps in funding are largely unknown at this point, it is still important to begin the discourse.

One promising possibility in funding could lie within the context of government funding programs. Grants for Native American programs are widely available, and as previously mentioned, tribes and government agencies have partnered to produce programs that are shown to be positively influential for Native American individuals seeking cultural reintegration. In briefly reviewing the application process for government funding, it appears that applying for grant money is a lengthy and involved process. However, the theoretical support for a Native American culture-focused music 
therapy program is evident, so perhaps with the right partnerships, funding could be achieved through government grants and tribal contributions in supporting this proposed program.

In addition to funding, there is the matter of training and recruiting program facilitators, a matter that must be addressed as part of the design of the program. Because the proposed culture-focused music therapy program is a largely novel pursuit, there is no existing training manual for facilitators of the program. Currently, there appears to be two possible logical avenues for training.

There are essentially two sets of core knowledge that influence the culturefocused music therapy program, and these sets of core knowledge are found in the name of the program; namely, cultural knowledge, and music therapy knowledge. The most efficient system would likely be that facilitators would have a background in one set of knowledge, and need to be trained in the other. Though it would be ideal if facilitators had knowledge in both Native American culture and music therapy practices, the odds of finding individuals with that specific existing knowledge set are likely quite improbable, though perhaps not impossible. However, given the more likely scenario, the question remains: is it preferable to train music therapists to apply Native American cultural empowerment to their practice, or is it preferable to train Native American cultural experts to apply music therapy methods to their practice?

Because this proposed program would seek to empower and unite people of a culture, it might be preferred to train individuals within the culture to facilitate cultural empowerment through the use of music. Especially because Native American music is already so deeply ingrained within Native American culture and spirituality, it might be 
more beneficial to keep as much of the therapy program within the tribe as possible. Many Native American individuals have grown understandably wary of outsiders after decades of historical mistreatment and prosecution from "White American" society (Evans-Pritchard, 1989). As a result, it may be in the best interest of Native American individuals and the program's efficacy to promote cultural empowerment through music from the inside of the Native American culture, rather than bringing in outsiders to reintegrate Native American individuals into a culture of which the outsider would potentially have little or no authentic connection to the culture.

In this regard, the optimal design of recruitment might be to meet with members of tribes or Native American communities that are interested in the program, and elucidate the theoretical background of the program and what it seeks to accomplish. Once this is understood between all potential partners, a discourse could take place to begin to determine if there are members of the tribe or Native American community who could operate as ideal facilitators to be trained to lead the program. These individuals could be elders with invaluable cultural and spiritual knowledge, members with backgrounds in health and healing practices, or even Native American musicians. In fact, the program might ideally be led by a group of qualified Native American individuals rather than a single qualified facilitator to help provide a more comprehensive marriage of Native American music, culture, and healing.

Lastly, the participant construct of the program needs to be determined. This is an aspect that holds very flexible parameters in the design of this proposed program.

Obviously, the program seeks to heal individuals first, so the ideal participant would be one who appears to be experiencing the psychological pains of acculturative stress. An 
initial assessment intake process similar to that used in current music therapy programs could help determine what individuals suffering from adverse acculturative stress issues need in participation in culture-focused music therapy.

It is also important to reach out to individuals outside of the tribe who are suffering from acculturative stress issues; these individuals may be experiencing significant acculturative stress due to a greater lack of cultural integration, as they could be far removed from Native American cultural exposure. These members could potentially be thoroughly difficult to locate. Strategies to do locate such Native American individuals might include partnering with urban mental health facilities to determine if there might be any Native American individuals suffering from acculturative stress among their clientele. Additionally, advertising for the program could take place through venues such as urban community centers and neighborhoods with high Native American populations living outside of their traditional culture community, or even reaching out through media such as online or print materials to increase program awareness.

Although recruitment could be difficult, the good news is that a wide target could be set for participants. Given the nature of this proposed program, really anyone could likely benefit from participating, as long as they identify with the culture group that is hosting the program. Even if participants are already secure and well versed in their own traditional culture knowledge, the process of engaging with music in a unified group is a healthy activity in and of itself. Further, it might be beneficial for other participants who are not integrated within their heritage culture to spend time with those participants who are well integrated with their heritage culture. As far as participant design, the vision for 
this program is more of an open environment where members of a unified culture, young and old, previously involved or not, are coming together to learn about their culture and music, to be empowered through their culture and music, and to heal through their culture and music.

Lastly, an important aspect of the design of the program is the location and duration, specifically where, when, and how long the program would take place. Ideally, these factors would be determined by the specific tribal context in which the program was to be implemented. If anything, this program is envisioned to be a fully tailored program. Native American individuals are unique as a people, and different tribes, though they share much in common, are still different from each other. Keeping this in mind, the program is to be constructed around the needs of the tribes or communities in which it is implemented.

The culture-focused music therapy program could be implemented into any Native American tribe or community in which the members are willing and engaged with the concept of the program. It would be especially ideal in Native American communities where other forms of intervention for its suffering members have been otherwise unsuccessful or nonexistent. However, anywhere there is a need and a desire for a Native American culture-focused music therapy program would be an ideal location.

Following the spirit of customization, aspects such as when the program would take place would be modified in accordance with the needs of both participants and facilitators. The program should operate during a time and in a place where everyone who wants to participate can freely do so. Perhaps several programs a week held in a 
place of community gathering space could accommodate all interested members of the participating tribe.

As far as the length of the program, it would need to persist at least until participants are showing signs of improvement (i.e. reduced symptoms of acculturative stress) or until participants are dropping out, in which case the program may need to be reevaluated. However in the case that the program were creating a positive impact, there is no reason why the program should ever have to really conclude. Obviously those in the greatest need of assistance would require priority for healing, but even those who have healed could potentially continue to participate and enjoy the healing process of engaging with music and heritage culture. In fact, the program could potentially branch into a community activity, wherein members of the community participate with each other through music, strengthen community bonds, and heal together. Perhaps the program could even host annual concerts or other events to branch into an enduring community entity. In this fashion, the program could evolve into a community custom in addition to a therapeutic intervention, and would never really have to have a set termination date. A lifelong engagement with music, culture and community could surely be optimal for optimal psychological health and overall well-being.

Assembling the Program

Once all these aspects of program design are developed, a more dynamic picture of the program begins to take shape. The program will ideally employ a partnership of proven aspects of music therapy and cultural education and empowerment to help heal Native American individuals suffering from a disproportionate amount of mental health 
issues related to acculturative stress. This proposed program could be funded through a partnership between government agencies and tribal institutions. Members of the tribe or community rather than outsiders would facilitate the program to help increase cultural cohesion, unity and empowerment. Facilitators would be trained in the spirit and goals of the proposed program, and would be sure to have a firm grasp of cultural knowledge and understanding of healing and music as a therapeutic force. A team of facilitators leading the program, rather than an individual facilitator, could likely better accomplish the translation of this necessary wealth of knowledge. Participants would ideally be any Native American individuals suffering from acculturative stress, however the program could be a potential healing process for any and all members of the community. Many details of the program, such as time, place and duration, would be customized to the needs of the participating Native American tribe or community.

With a more complete picture of what the proposed Native American culturefocused music therapy program might look like and how it might function, the next step in theorizing implementation would be implications for measures of the program's efficacy.

\section{Hypothetical Study Design}

Determining the efficacy of the proposed culture-focused music therapy program is crucial in understanding whether or not the program is a valuable use of time and resources, and in ascertaining if the program is actually helping people to heal or not. Designing a study to measure whether or not the program is an effective therapeutic intervention is a useful endeavor on multiple fronts. First, a study would allow for a trial 
run of the proposed program, enabling the ability to better discern if the current program blueprint is translating well to the actual program application. It also allows for a gauge of how well, if it all, the program is accomplishing what it's intended to accomplish. This could aid in validating the program, funding the program and spreading word of the program to other Native American communities and tribes.

\section{Setting up the Study}

The first step in designing the study is to determine research methods and participant details. For a trial of the program, it would first be necessary to partner with a Native American community or tribe interested in testing the program. Access would be required for a population of potential participants and facilitators within a Native American tribe or community, a location for a trial run of the program, and other tribal resources, such as music, instruments and cultural knowledge of the given culture. Details of the extant research, the proposed program, and the intended healing goals of the proposed program would be presented to interested Native American tribes or communities. Once a partnership is established with an interested Native American tribe or community, the study can begin to take shape around the specific needs of the Native American tribe or community.

The study itself would essentially be a trial run of the program, as previously outlined, to be implemented into the interested Native American tribe or community for a determined length of time. Eight to ten weeks should be sufficient for data collection. Additionally, a discourse with the participating Native American tribe or community would need to occur to determine where and when the program would take place. Next, 
potential facilitators of the program would need to be identified within the specific Native American culture group and would need to participate in training to prepare for leading a program combining cultural knowledge and music therapy methods. Once these details are established and solidified, recruitment measures could be designed and implemented.

\section{Risks and Recruitment}

In beginning to recruit participants, it is of the utmost importance that level of risk in participating in the trial is of an acceptable degree, meaning that the potential benefit of the program would far outweigh any potential risk. Determining potential for risk is a precarious but necessary pursuit. In this program, the potential risk would likely fall under the "minimal risk" category as outlined by the Portland State University Human Subjects Research IRB application (Human Subjects Research Review Committee, 2013).

A minimal risk level means that participants would not experience any more risk while engaging in this program than they would while participating in daily activities or examinations and therapies expected from routine medical and/or psychological appointments (Human Subjects Research Review Committee, 2013). In the proposed program, it is not anticipated that participants would experience an increased risk for physical, legal or economic harm. Additionally, there are no anticipated risks of coercion, or threats to employment status. The only foreseeable potential risks in participating in the proposed program would be psychological or social in nature.

Because participants would be dealing directly with psychological issues, (i.e., those associated with acculturative stress) there is a potential for psychological 
discomfort and/or pain resulting from program participation. Sometimes dealing with psychological issues can result in psychological pain or discomfort, or can activate or recall psychological issues that were previously dormant. Additionally, part of the cultural education and empowerment section of the program could stir up psychological and emotional issues related to the history of persecution of Native American culture. Because of this, and due to the nature of expressing and working through psychological issues, there is a potential risk of psychological pain and/or discomfort.

Additionally, much of the proposed program hinges upon social aspects, such as cultural and community engagement and working with other diverse members of the tribe or community. Bringing more and less traditional culture-identified Native American individuals together could result in certain social risks. An example of this type of risk might be ridicule, alienation, or persecution of participants who were previously completely segregated from their culture. These individuals who lived or were born outside of the Native American tribe or community might be treated as outsiders, which could result in the potential risk of social tension.

Although there are prospective risks inherent in the nature of the program, the potential for healing and combating acculturative stress through music and heritage culture identity empowerment and education would likely outweigh these potential risks. Also recall the potential to develop increased specialized resiliency in associating with heritage Native American culture. Further, there would be safeguards built in to the program to insure safety of all participants. These same safeguards would extend beyond the study and would be a permanent aspect of the nature of the final program as well. 
Confidentiality and anonymity are safeguards that would be employed to help protect participants dealing with psychological and emotional issues. Some participants might otherwise experience stress or feel anxiety over the fact that their personal psychological issues, emotions and thoughts are being explored and expressed through music activities, however this will always be safely guarded information. Psychological exploration and expression can be a deeply personal and private matter, so it is of the utmost importance that whenever participants wish to exercise anonymity that they can freely and effortlessly do so. Anonymity would mean that the participant's identity within a given activity is unknown to everyone, both other participants and facilitators alike of the participant desires. Confidentiality would mean that although researchers or facilitators could identify participants based off of certain activities in the program, this information would be kept private and would not be shared with others.

Additionally, because the program would be heavily focused on cultural education and empowerment, a theme of unity would be promoted between all people of a given culture. Recall that the process of engaging in and working together through music, especially the music therapy method of group singing, has been shown to decrease isolation and increase group cohesion. A persistent spirit of unity and group cohesion established through the design of the program could ideally mitigate social risks for Native American individuals who were previously disconnected from the culture attempting to reintegrate into their traditional heritage culture.

Lastly, the process of informed consent is a participant safety measure federally required before any research dealing with mental health (Human Subjects Research Review Committee, 2013). Obtaining informed consent is a process that includes 
adequately informing subjects in regards to the research, potential risks and their rights to the point that potential participants are able to reach an educated decision as to whether or not they would like to partake in the study. This is important in ensuring that participants are capable of making safe and responsible decisions in regards to their level of involvement.

With a blueprint of recruitment methods and participant safety established, the methods for research must be designed in the process of setting up the study.

\section{Research Methods}

For the purposes of this study, an eight to ten week trial run with a sample population of Native American individuals struggling with acculturative stress would be consummate to study the application of the proposed culture-focused music therapy program. For this study phase of the program implementation, participants would be restricted to Native American individuals struggling with acculturative stress; this is due to the fact that the study would first seek to establish that the program is effective in treating acculturative stress before it seeks to demonstrate the broader notion that the program is effective in positively impacting people regardless of presence of acculturative stress.

The sample population would be coded as having acculturative stress. This could be accomplished by utilizing the comprehensive Social, Attitudinal, Familial, and Environmental Acculturative Stress Scale, developed by Mena et al. (1987). This is a 24item scale testing the level of acculturative stress experienced by participants by scoring survey items rated on a 1 (not stressful) to 5 (very stressful) scale. The sample 
population could be selected in accordance with a certain score or higher based on the Social, Attitudinal, Familial, and Environmental Acculturative Stress Scale.

Additionally, participants could reflect upon their current mental health and emotional state in controlled interviews prior to the study.

After the sample population is established, the population would be randomly split into two groups: a control group and a treatment group. The control group would receive no culture-focused music therapy treatment, while the treatment group would receive the trial of the culture-focused music therapy program.

During the eight to ten week study period, controlled interviews could continue to occur perhaps weekly or biweekly to track any changes in mental health and emotional state. After the eight to ten week study period, participants could take a final interview, as well as retake the Social, Attitudinal, Familial, and Environmental Acculturative Stress Scale to track changes in level of acculturative stress and overall well-being.

Based on existing research, the hypothesis would be that participating in the Native American culture-focused music therapy program would successfully combat acculturative stress for Native American individuals by increasing traditional culture identity integration, cultural empowerment, group cohesion, and by an engagement with music.

\section{Measures of Success}

If the data collected from the study were found to be statistically significant towards a negative correlation of increased time spent in the program with decreased level of acculturative stress when compared to the control group, then it could be 
suggested that the culture-focused music therapy program helped Native American individuals to mitigate the effects of acculturative stress. From this point, it would be beneficial to replicate the study with another sample population and analyze for validity and reliability of the data. If it were found that the data collected were indicative of the efficacy of the culture-focused music therapy program, then this would measure the success of the program in achieving its intended goal of healing by attenuating the adverse effects of acculturative stress.

Further, to underscore the efficacy of the program and to suggest its universal appeal in assuaging acculturative stress, the study could be replicated with several different Native American tribes and communities. If the program were found to be successful in helping to thwart acculturative stress for many diverse Native American tribes, then it would have implications for a wide range of effective use in helping Native American individuals all over the country. These implications would be vastly important considering the apparent need for intervention and the potential good such an intervention could do for Native American populations.

\section{Conclusion}

In review, extant research has shown that Native American populations experience a disproportionately higher amount of mental health issues compared to other population groups in the United States (APA, 2010). Many of these mental health issues are associated with the process of acculturation and the resulting acculturative stress. These mental health issues related to acculturative stress can greatly impact overall wellbeing and healthy psychological functioning. Given the current landscape of widespread 
mental health issues in many Native American populations, there is a crucial need for an intervention to address these mental health issues associated with acculturative stress.

Research has also suggested that increasing heritage culture identity exposure and retention can significantly mitigate the effects of acculturation (Bradway, 2011; Lester, 1999). Further, to add to the need of Native American populations increasing traditional exposure into their own culture, research has suggested that Native American culture could provide specialized resiliency in promoting psychological well-being (Bradway, 2011).

An intervention seeking to empower cultural identity would likely benefit from utilizing the strengths of the culture. In the case of many cultures, but especially Native American culture, music is an integral aspect of the historical, cultural and spiritual context of the people (Wallin, 200; Wiand, 2004). Additionally, music has been shown to be a powerful therapeutic intervention in and of itself (De Backer, 2005; Grocke et al., 2009; Hamill, 2009; Hinton, 2008; Sacks, 2008). As a result, the notion of combining the culturally relevant and therapeutically effective construct of music with the notion of empowering traditional heritage culture could be a highly effective means of combating acculturative stress within Native American populations.

This theory culminates in the theoretical design of a culture-focused music therapy program to combat the negative effects of the process of acculturation. Such a program is merely theoretical in design, but the design is the first step towards actual implementation. The program would be partially founded on the universal and proven strategies in contemporary music therapy (as previously discussed). The proposed program would combine these methods with a strong emphasis on cultural education and 
empowerment. The program would be facilitated from within the Native American tribe or community to help strengthen cultural and communal ties. Participants would be selected based off need, however the program would likely benefit anyone participating in the engagement of music and cultural learning and empowerment.

The program would be rigorously tested before widespread implementation. Based upon the current research, the proposed culture-focused music therapy program should be effective in mitigating and combating the harmful effects of acculturative stress for participants partaking in the program. Regardless of what research might suggest, the program might perform differently in actual implementation, therefore a controlled trial of the program would be necessary to assess whether or not the program operates as research suggests it should. Further, any intervention dealing with psychological issues carries the potential risk of psychological harm. However given the nature of the proposed culture-focused music therapy program, the potential benefits suggested by research would outweigh the potential risks of any psychological harm in participation of the program. Moreover, a controlled trial of the program would help to ensure that the program achieves more positive effect than negative effect.

Should the controlled trial of the culture-focused music therapy program prove be successful, this would have globally relevant implications. As research has shown, the process of acculturation and associated acculturative stress is a global phenomenon. As such, acculturative stress is an entity that affects people all over the world, regardless of ethnic culture identity (Berry et al., 2006). Currently the proposed culture-focused music therapy program focuses on Native American populations due to the immediate need consequential on a disproportionate burden of mental health issues and an inadequate 
representation in the research field. However if the program were to demonstrate efficacy in attenuating acculturative stress for different Native American tribes and communities, then the program could potentially be adjusted by tweaking and customizing the cultural and musical aspects of the program, so as to be applicable to many diverse cultures throughout the world. In this fashion, the culture-focused music therapy program could be applicable to a global scale in combating acculturative stress.

The cultural and social landscape of the modern world is progressively changing. Perhaps as mankind continues to commingle, and as different cultures come into contact with one another, understanding and acceptance of diverse people can result. Notwithstanding, the potential downside of increasing homogeneity is that, in the constant churning of the melting pot, sometimes minority cultures can begin to pale or vanish under the penumbra of dominant cultures. Essentially, acculturative stress is the byproduct of attempting to relinquish part or all of an individual's heritage cultural identity in order to assimilate into a dominant culture. The negative mental health issues associated with acculturative stress are significant aspects affecting overall well-being. If this proposed program demonstrates that traditional heritage culture identity can be empowered and enlivened through the therapeutic use of music, then this culture-focused music therapy program could potentially aid people the world over. This is all part of a construct of future research that would be required should the program in fact prove to be effective for Native American populations.

However presently, the proposed culture-focused music therapy program seeks to lend aid to a people of a rich culture of music, healing, and spirituality, a people who have been wrongly persecuted, abused and then neglected for centuries. If the proposed 
culture-focused music therapy program were to produce evidence to suggest that it was able to evoke a positive impact for any individual or individuals of the Native American community, it will have made a significant, just, and positive impact in the world. 


\section{References}

American Indian Policy Center. (2005). Reflections on traditional American Indian ways: Challenges for the younger generations. American Indian Policy Center.

American Music Therapy Association (AMTA). (2013). What is music therapy? Retrieved from http://www.musictherapy.org/about/musictherapy/

American Psychiatric Association. (2010). Mental health disparities: American Indians and Alaska natives. American Psychiatric Association, Office of Minority and National Affairs. Retrieved from www.psych.org.

Berry, J. W. (1997). Immigration, acculturation, and adaptation. Applied Psychology: An International Review, 46(1), 5-68.

Berry, J. W., Phinney, J. S., Sam, D. L. \& Vedder, P. (2006). Immigrant youth: Acculturation, identity, and adaptation. Applied Psychology: An International Review, 55(3), 303-332. doi: 10.1111/j.1464-0597.2006.00256.x

Borowsky, I. S., et al. (1999) Suicide attempts among American Indian and Alaska native youth: Risk and protective factors. Archives of Pediatrics and Adolescent Medicine, 153(6), 57380. 
Bradway, B. (2011). Correlates of resilience among American Indians in a northwestern US state. UMI Dissertation Publishing.

Brown, J. M. (2002). Towards a culturally centered music therapy practice. Voices: A World Forum for Music Therapy, 2(1). Retrieved from https://normt.uib.no/index.php/voices/article/viewArticle/72/62

Buriel, R., Calazada, S., \& Vasquez, R. (1982). The relationship of traditional Mexican Ameri-can culture to adjustment and delinquency among three generations of Mexican American male adolescents. Hispanic Journal of Behavioral Sciences, 4, $41-55$.

Castro, F. G. (2007). Is acculturation really detrimental to health? American Journal of Public Health, 97(7), 1162-1162. doi: 10.2105/AJPH.2007.116145

Crockett, L. J., et al. (2007). Acculturative stress, social support, and coping: Relations to psychological adjustment among Mexican American college students. Faculty Publications, Department of Psychology. Paper 299.

De Backer, J. (2005). Music and psychosis: The transition from sensorial play to musical form by psychotic patients in a music therapeutic process. Unpublished PhD dissertation, Aalborg University, Denmark. 
Downs, M., Nguyen, J. H., \& Johnson, B. (2013). NEH supports strategic collaborations in Native American history, languages, and cultural revitalization. National Endowment for the Humanities. Retrieved from http://www.neh.gov/news/neh-supports-strategic-collaborations-in-nativeamerican-history-languages-and-cultural

Evans-Pritchard, D. (1998). How 'they' see 'us': Native American images of tourists. Annals of Tourism Research, 16, 89-105.

Friedman, M. (2014). Does music have healing powers? Psychology Today. Retrieved from http://www.psychologytoday.com/blog/brick-brick/201402/does-musichave-healing-powers

Garrett, M. T., \& Pichette, E. F. (2000). Red as an apple: Native American acculturation and counseling with or without reservation. Journal of Counseling and Development, 78, 3-13.

Gil, A. G., Vega, W. A., \& Dimas, J. M. (1994). Acculturative stress and personal adjustment among Hispanic adolescent boys. Journal of Community Psychology, $22,43-54$. 
Grocke, D., Bloch, S., \& Castle, D. (2009). The effect of group music therapy on quality of life for participants living with a severe and enduring mental illness. Journal of Music Therapy, 46(2), 90-104.

Hamill, C. H. (2009). Songs from spirit: Power and prayer in the Columbia plateau. Proquest LLC.

Hinton, D. (2008). Healing through flexibility primers. The Oxford Handbook of Medical Ethnomusicology, 121-163.

Human Subjects Research Review Committee. (2013). IRB application/protocol. Portland State University.

Koen, B. D. (2013). "My heart opens and my spirit flies": Musical exemplars of psychological flexibility in health and healing. Ethos, 41(2), 174-198. doi: 10.1111/etho.12014

Lester, D. (1999). Native American suicide rates, acculturation stress and traditional integration. Psychological Reports, 84(2). doi: 10.2466/pr0.1999.84.2.398

Marielena, L., Gamboa, C., Kahramanian, M. I., Morales, L. S., \& Bautista, D. F. H. (2005). Acculturation and Latino health in the United States: A review of the literature and its sociopolitical context. Аnnu. Rev. Public Health, 26, 367-97. doi: 10.1146/annurev.publhealth.26.021304.144615 
Miranda, A. O., Bilot, J. M., Peluso, P. R., Berman, K., \& Van Meek, L. G. (2006). Latino families: The relevance of the connection among acculturation, family dynamics, and health for family counseling research and practice. The Family Journal: Counseling and Therapy for Couples and Families, 14, 268-273.

Ngo, V. H. (2008). A critical examination of acculturation theories. Critical Social Work, 9(1). Retrieved from http://www1.uwindsor.ca/criticalsocialwork/a-criticalexamination-of-acculturation-theories

Pavlicevic, M., Trevarthen, C., \& Duncan, J. (1994). Improvisational music therapy and the rehabilitation of persons suffering from chronic schizophrenia. Journal of Music Therapy, 31(2), 86-104.

Prinzing, S. S. (2009). American Indian music: More than just flutes and drums. Montana Office of Public Instruction.

Revitalizing Native cultures. (2006). Native American Public Telecommunications. PBS. Retrieved from http://www.pbs.org/indiancountry/challenges/cultures.html

Rickard, N. S., \& McFerran K. (2012). Lifelong engagement with music: Benefits for mental health and well-being. New York, NY: Nova Science Publishers. 
Sacks, O. (2008). Musicophelia: Tales of music and the brain. New York, NY: Random House.

Samaniego, R. Y., Gonzales, N. A. (1999). Multiple mediators of the effects of acculturation status on delinquency for Mexican American adolescents. American Journal of Community Psychology, 27(2).

Schiefer, D., Krahé, B. (2014). Ethnic identity and orientation to white American culture are linked to well-being among American Indians - but in different ways. Social Psychology. (45)1. 1-14. doi: 10.1027/1864-9335/a000155

Soderholm, P. (2001). Music of the people- Native American music. Colorado Unit Writing Project.

Stige, B. (2002). Culture-centered Music Therapy. Gilsum, NH: Barcelona Publishers.

Sundar, S. (2007). Addressing diversities in music therapy theory, practice and research: Major challenges. Voices: A World Forum for Music Therapy, 7(1). Retrieved from https://voices.no/index.php/voices/article/viewArticle/468/377

Suicide Prevention Resource Center. (2013). Suicide among racial/ethnic populations in the U.S.: American Indians/Alaska Natives. Waltham, MA: Education Development Center, Inc. 
Szapocznik, J., Kurtines, W. (1980). Acculturation, biculturalism, and adjustment among Cuban Americans. In A. M. Padilla (Ed.), Acculturation: Theory, models and some new findings (pp. 139-157). Boulder, CO: Westview.

United Nations Population Division. (2002). World immigration report. New York: United Nations.

Wallin, N. L., Brown, S., Merker, B. (2001). The Origins of Music. Cambridge: MIT Press.

Wiand, L. L. (2004). The effects of sacred/shamanic music on trauma related disorders: Dissociative disorders and music of an indigenous Native American flute. ProQuest Information and Learning Company.

Wishart, D. J. (2011). Native American music. University of Nebraska-Lincoln. Retrieved from http://plainshumanities.unl.edu/encyclopedia/doc/egp.mus.034

Young-Mason, J. (2002). Music therapy: A healing art. Clinical Nurse Specialist. 16(3). 153-154. 